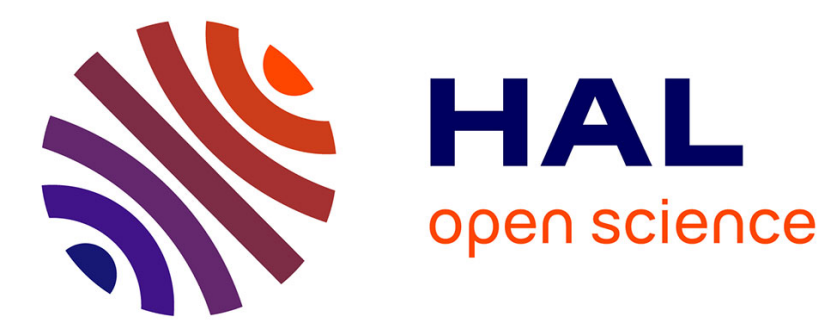

\title{
Is the New Economy a Useful Concept?
}

Bernard Paulré

\section{To cite this version:}

Bernard Paulré. Is the New Economy a Useful Concept?. 2000. halshs-00226422

\section{HAL Id: halshs-00226422 \\ https://shs.hal.science/halshs-00226422}

Preprint submitted on 30 Jan 2008

HAL is a multi-disciplinary open access archive for the deposit and dissemination of scientific research documents, whether they are published or not. The documents may come from teaching and research institutions in France or abroad, or from public or private research centers.
L'archive ouverte pluridisciplinaire HAL, est destinée au dépôt et à la diffusion de documents scientifiques de niveau recherche, publiés ou non, émanant des établissements d'enseignement et de recherche français ou étrangers, des laboratoires publics ou privés. 


\title{
Is the New Economy a Useful Concept?
}

\author{
Bernard PAULRE * \\ Université Paris 1 Panthéon Sorbonne \\ MATISSE UMR CNRS n 8595
}

July 2000

\begin{abstract}
The present paper examines the meaning and usefulness of the concept of a New Economy. This construct, which first began to appear in the media in the mid-1990s, is utilised today with a variety of definitions and intentions. Having identified three possible denotations or orientations relating to its current usage, we suggest that the original meaning, and the language that is associated with it, express an extremely optimistic view of the future of the U.S. economy, and are best classified as being utopian. We also examine the validity and significance of the theses developed by the radical proponents of the New Economy concept by testing them against a certain number of facts and statistical studies concerning the state of the U.S. economy for the past ten years. By studying the substance of these New Economy theses, we discover an inconsistency between one of the concept's basic principles (the advance of technological progress, driven by the information and communications technologies that are allegedly diffusing throughout the whole economic system) and that which we already know about the evolution of two different forms of productivity (the productivity of labour and total factor productivity) - including the way in which they have diverged in the various economic sectors. We mention a few alternative approaches that can be used to analyse the ongoing economic growth in the U.S. Until now, macroeconomic growth models have provided the theoretical underpinnings for most debates on the origins of the particular economic growth and productivity gains that have taken place in the current environment. However, the present study shows that given the nature of the issues that need to be resolved, we should also be taking a look at problems that are more global in nature, i.e., the existence of quantum leaps in technology, and hence the theory of long-term technological change. Our conclusions emphasise the confusion that the New Economy concept can cause, and we evoke Solow's Paradox, which we see as still being applicable in today's situation, albeit in a modified form.
\end{abstract}

\footnotetext{
* Laboratoire MATISSE- I.SY.S. (Innovation - Systèmes - Stratégies), Université de Paris 1 Panthéon Sorbonne, paulre@univ-paris1.fr. The author's research into the New Economy has benefited from the kind support of the Institute CDC (Caisses des Dépôts et Consignations, Paris). Of course, the opinions expressed in the present paper are the author's alone, and do not necessarily reflect the opinions of the Caisse des Dépôts et Consignations. Many thanks to Alan Sitkin for his suggestions and his very relevant translation, and to Centre Saint-Gobain pour la Recherche en Economie and Jean-Philippe Touffut for their kindly translation's support.
} 


\title{
Is the New Economy a Useful Concept?
}

\author{
Bernard Paulré
}

\section{Introduction}

The situation that the United States experienced during the 1990s was, strictly speaking, a novel one. Representing the grouping of a certain number of original economic, social, and political characteristics, set against a new international environment, this combination, from a historical point of view at least, was definitely unique.

However, those analysts who turn to the concept of a New Economy to describe the United States' economic situation during the 1990s and now, at the dawn of new century, generally intend to signify something quite different. First of all, they are trying to stress that the U.S. economy finds itself in situation that has never occurred in the past, i.e., a particularly long growth phase combined with accelerated productivity gains and historically low inflation and unemployment rates. They assert that the U.S. economy's current trends have lead to the abolition of certain economic laws previously considered to be fundamental (the existence of cycles, or of inflationary pressures, for example). This is allegedly due to the rise of new information and communications technologies (henceforth called ICT), that is, essentially to the advent of a new techno-economic paradigm, and to globalisation.

Note that economists had been focusing for quite some time on the absence of any apparent macroeconomic effects from the advance of ICT - that is to say, on the absence of any net observable effects on growth and on productivity. Solow's Paradox, in and on itself, offered a succinct picture of how difficult it is to analysis of this phenomenon (1). In essence: we know that economic agents have invested a great deal of money in computers - yet there has been no observable effect in terms of productivity or growth, insofar as these effects can be globally measured through the use of existing statistical systems. Even worse, the advance of information technology has taken place at a time when we have witnessed (starting in 1973, according to certain observers) a slowdown in productivity (2). There had already been polemics between those who stressed the inadequacy of a statistical system designed at a time when productive activities were basically related to manufacturing; and those who (possibly with some regret) had resigned themselves to accepting whatever the statistics were showing.

The problem grew and changed parameters when certain observers began to assert that the American economy had entered into a golden era of extended economic growth during the 1990s (a virtuous circle, i.e., something akin to perfect economic dynamics) (3). This contradicted what economists thought that knew about growth, and about cycles. Not only did growth seem particularly robust and unusually long lasting during the 1990s, but the average productivity of labour also rose. Its average annual rate between 1991 and late 1994 was 2.2 \%, markedly higher than its trend during the 1970s and 1980s $(1.1 \%)(4)$. Wall Street made records highs, one after the other, and company valuations reached incredible levels - sometimes with firms that had never even recorded the slightest profit.

Statistically speaking, the new rate of productivity growth, when analysed over a 4 year period, was not significant enough to justify anyone's saying that the Solow Paradox was dead and buried. However, in light of the American economy's macroeconomic performances, it became tempting to rely on ICT as an explanation; and to aver that these performances constituted the first tangible and specifically 
economic manifestations of the rise of ICT. Hence the concept of a New Economy, a theme that first appeared in Business Week in 1994, and whose definition was dealt with explicitly from 1997 onwards.

Since this time, the New Economy concept has permeated the entire media. Since the United States has maintained these high levels of economic performance, the concept has become a recurring theme, even a magical incantation, which holds that the developed economies should be able to follow the United States into this new era of prosperity.

On 5 April 2000, the White House held a conference devoted to the New Economy. President Clinton, after a few words of welcome, opened the proceedings by stating: "We meet in the midst of the longest economic expansion in our history, and an economic transformation as profound as the one that led us into the Industrial Revolution." Moreover, the topics that were dealt with during this conference did not include any detailed characterisation of this unusual situation. They went even further - "This conference is a designed to focus on the big issue of the New Economy: how do we keep this expansion going? ..."

This quote highlights the point that we are making with respect to the New Economy: its reality is considered to be self-evident, that is, no doubt is cast upon it. The only problems that are ever mentioned concern the way in which it should be "managed": how to keep the movement going, correct its negative manifestations, etc.

It has become impossible to get away from this New Economy concept. It has permeated the media, and become part of today's vocabulary to such an extent that it can seem incongruous nowadays to even try to question its real meaning and significance. Yet people can vary greatly in their understanding of this concept; it designates phenomena whose reality is questionable; and it has attained a status that needs to be discussed.

In addition, the ongoing economic changes that have been described and highlighted by the radical proponents of the New Economy thesis are so significant that they can leave no economist indifferent. Indeed, we should recognise the enigmatic nature of several aspects of the U.S. economy's performances and characteristics during the 1990s. The fact that it is considered appropriate to use the term "paradox" when discussing these phenomena justifies further examination. There is nevertheless the risk that economists who investigate such theses, and who discover that they contain a certain number of shortcomings, risks or incoherencies, will be labelled killjoys or doubting Thomases. Yet is this not the role that economists have been usually asked to fulfil? The profession after all has a long and uninterrupted tradition of scepticism...

One after the other, we will be looking at the following issues and topics: (i) the denotations and characteristics of this New Economy concept: what do people mean when they wield it? (ii) an empirical and statistical discussion of these New Economy theses, and of its description as a utopia, (iii) thinking on how to best analyse the United States' economic situation during the 1990s (5). We conclude by drawing attention to the confusion that can be fostered by the New Economy concept, and we return to the Solow Paradox, which remains topical, albeit in need of modification.

\section{The various meanings of a relatively vague concept}


The New Economy concept has been associated with an extremely wide variety of meanings. In and of itself, this is not surprising, if only because the notion of novelty is inevitably relative and/or subjective. Moreover, we have had to deal with a certain number of expressions that are in fact synonymous: "the long boom" (coined by Wired magazine and by the OECD); " the digital economy" and/or "the electronic economy" (expressions used by the U.S. Department of Commerce's Economics and Statistics Administration); the "weightless economy" (c.f. D. Coyle and D. Quah) etc. The variety of this semantic range is such that the only objective we can set ourselves in the present analysis is to introduce the concept's accepted denotations and characteristic orientations. As a result, we will be trying to come up with a typology of the possible meanings of the expression New Economy, without presenting the sum total of its variations.

With this in mind, we affirm that the New Economy concept can have three significantly different meanings. Depending on who is using it, the term can designate: (i) a subset of those economic activities that encompass ICT, (ii) the U.S. economy's recent performances, and several characteristic features of its current situation - whose surprising or original nature we recognise even though we are not willing to affirm that these new attributes necessarily translate any definitive structural change in the U.S. economy, (iii) the technological and economic revolution that the U.S. is currently experiencing, of which these surprising economic performances are the first but not the only symptoms (with many people feeling that these performances will continue for the foreseeable future).

The original New Economy concept is the third one in this typology. To appreciate its impact, we need to remember that this particular definition was forged between 1995 and 1997, that is, at a time when the performances of the American economy, although already worthy of note, were not yet as remarkable as they are today. Given that the current expansion phase actually started in March 1991, the concept under discussion first appeared towards the end of the cycle's fourth year of existence. This meaning of the concept expresses an optimistic attitude that we will label "radical", given the deep-seated nature of the changes whose existence and significance it wishes to emphasise.

The two other notions reflect two attitudes and two conceptions that are clearly different from the "actual" New Economy. These ideas first appeared at a later date. The opacity and confusion that accompanies the utilisation of a New Economy concept stems from this plurality of meanings and attitudes - a multiplicity that we will now attempt to describe.

\section{The New Economy as a sector, with implications for the production and utilisation of new information and communication technologies (ICT)}

People increasingly use the term New Economy to describe that part of the economy which is devoted to the exploitation and development of ICT. This is a low-level meaning, and a relatively recent one, which has tended to replace the other definitions, despite their seniority. This new meaning has become particularly prevalent since stock market-related articles in the press have been invaded by a distinction between new and old economy stocks, that is to say, since the late 1990 s.

It seems to us that this particular understanding of the New Economy concept is subject to criticism. First of all, it does not correspond to that which had originally been called the New Economy, i.e., the term's third definition in the aforementioned typology, which conveys a broader meaning (see below). Secondly, we consider that the idea of splitting the economy into two separate sections is harmful. This would be tantamount to preserving a somewhat black-and-white view that consists of distinguishing within an economy between the "old" sectors, basically condemned to disappear, and tomorrow's 
sectors, imbued with new technologies and thus the bearers of all hope. Yet even if it is true that technological revolutions do occur, they do not consist of the creation of new technologies whose role is to supplant the older ones. In reality, and using as a starting point the new paradigms that are being developed, new outcomes are achieved with old resources; and what really takes place is a giant reshuffling. In other words, older technologies can just as easily be enhanced and stimulated by newer technologies. For example, the automobile sector is not going to disappear tomorrow - and neither will agribusiness or primary metalworking. Every sector is affected by electronics and computing - every sector will end up participating in e-business and exploiting the advances in telecommunications. Our thesis is that ICT involves technologies that are generic, and apt to be diffused. (6) We feel that the concept of a General Purpose Technology emphasises the universal nature of ICT, and its capacity for being generative.

We can immediately see the ambiguity of this initial approach to the New Economy concept by examining in detail how people have tried to categorise economic activities in their attempts to specify the content and spread of activities comprising "this particular sector". Given our conception of ICT, it is no surprise that a number difficulties and significant divergences arise.

Some analysts start with the idea that the sectors that are mainly involved in this technological revolution include both aspects of ICT (hardware and software), as well as the contents providing industries. According to D. Tapscott, "A new industrial sector is emerging from the convergence among computing (computers, software, services), communications (telephony, cable, satellite, wireless) and content (entertainment, publishing, information providers)... This interactive multimedia industry is narrowly defined as $10 \%$ of the U.S. GDP". (7)

The U.S. Department of Commerce has a different and original position with respect to its classification of information technology-using sectors: "The digital economy is comprised of e-commerce and information technology (IT)-producing and (IT)-using industries. (IT)-producing industries include computer hardware, software/services, communications equipment and communication services industries. E.S.A. defines industries as IT-using if they are among the top 15 industries as measured by either of two measures: IT net capital stock as a share of total equipment stock or IT investment per employee. This criterion results an approximately twenty 2-digit SIC industries being classified as IT-using ... E-commerce is any transaction completed over a computer-mediated network that involves the transfer of ownership or rights to use goods or services." (8) However, and rather curiously, the Digital Economy 2000 report published by the same U.S. Department of Commerce only focuses on IT-producing industries. (9)

The economist D. Quah has an original outlook. He is the creator of the "weightless economy" concept, "also described as the knowledge economy, the immaterial economy or simply the New Economy". This concept combines three elements: "One, information and communications technology. Two, intellectual property. And three, libraries and databases. The last of these includes carbon- and silicon-based creations, such as biotechnology, or electronic compilations of information." (10)

Above and beyond these definition issues, there are also quite a few measurement problems that are not specific to the evaluation of the activities encompassed by the New Economy concept - but which are probably more acutely manifested in this area. (11)

Using the notion of a New Economy to assert the originality of the current U.S. economic situation - without affirming that this reflects any major and irreversible structural change 
This conception of a New Economy, which we have studied in earlier texts under the term new economy (written with lowercase letters), expresses a questioning and a desire to analyse rather than a quasi-doctrinal response purporting to define the significance of the changes that have been taking place. Using this narrower meaning, we can state that Alan Greenspan has seemingly become a proponent of this idea of a new economy (with lowercase letters). This would be compatible with his refusal to believe in the end of inflation, and with his repeated public warnings against the stock markets' "irrational exuberance". (12)

There is no need to comment upon this particular utilisation of the concept under study. This had been the most frequent connotation of the term, before the aforementioned "sectorial" conception had ever cropped up. It translates an "intermediate" position between the ultra-optimism of the proponents of the original New Economy conception (our third definition of the term), and the negative or highly sceptical position of those who refuse this notion because they feel that the current characteristics of the U.S. economy are not sufficiently unusual to warrant the use of a special descriptor. Of course, there is a vast range of possible attitudes on this topic.

\section{Using the concept of a New Economy to describe a new macro-economic operating "regime" - one that some analysts consider to be virtuous and quasi-perfect; as a consequence of the penetration of ICT; and as having caused a definitive modification of a certain number of economic laws}

This is the original meaning attributed to the New Economy concept in the United States.

According to S. Shepard, chief editor of Business Week, a magazine that (together with Wired) has played a very active role in diffusing across the United States the theses that are associated with the New Economy concept: "By the New Economy, we mean two broad trends that have been underway for several years. The first is the globalisation of business. Simply put, capitalism is spreading around the world - if not full-blown capitalism, at least the introduction of market forces, freer trade, and widespread deregulation... The second trend is the revolution in information technology. These two broad trends... are undermining the old order, forcing business to restructure... The result: a radical restructuring that is making us more efficient. These trends can combine in powerful ways to raise Americans' standard of living, create jobs, spur entrepreneurial effort - and do all this without boosting inflation. To the believers in the New Economy, we have here the magic bullet -a way to return to the high-growth, low-inflation conditions of the 1950s and 1960s. Forget $2 \%$ real growth. We're talking 3\%, or even 4\%. Forget double-digit inflation and the natural rate of unemployment. We're talking stable prices. Forget hopelessness in the developing world. We're talking about raising living standards in India and Brazil."

Thus it is the digital economy, within which an ever-greater proportion of economic value is produced through the use of electronic tools or processes, that will lead the American economy into a new era of high productivity and rising wages. The reasoning behind this line of thinking is essentially as follows: ICT, and more specifically digital technology, are the sources of a sharp rise in productivity. This has a knock-on effect on economic growth. Given that a situation of full employment exists, demand will remain high, even when faced with the many new products or facilities that the new technologies are offering. However, the increase in demand has not lead to any increases in prices: because of the fierce competition that reigns domestically, including for these innovative products; and because of international competition. The economy can therefore sustain a relatively high rate of growth, around 
$4 \%$ to $5 \%$ per annum, without any inflationary consequences. New Economy radicals affirm that the statistical apparatus is not adapted to the developed world's new attributes. This statistical battery had been essentially devised to measure a stable economy in which most production was comprised of agricultural or manufactured goods.

This "radical" or optimistic approach to the New Economy is manifested in a number of different ways. Here are a few examples to illustrate both their variety, as well as their convergence with respect to a few characteristic options.

In Wired, we find what we consider to be the text that best exemplifies the different derivatives of the New Economy concept. Entitled The Long Boom, this article is co-authored by P. Schwartz et P. Leyden. (14) The first is a consultant at Wired, the second a co-editor. The length of this text is very unusual for the magazine, demonstrating how important it was for the editorial team. The vision offered therein presents a "positive" and "plausible" scenario of the way in which the economic situation might develop between now and the year 2020. "Plausible" because it revolves around current technological or economic trends, hence not around a crucial hypothesis involving some future quantum leap. "Positive" because it is useable: "Without an expansive vision of the future, people tend to get short-sighted and mean-spirited, looking out only for themselves." Principles for interpreting the New Economy are stated clearly in this text: "From a historical vantage point, two developments start around 1980 that will have profound consequences for the U.S. economy... One is the introduction of personal computers. The other is the break up of the Bell System. These events triggered two of the five great waves of technological change that will eventually help fuel the long boom." (15) Productivity gains are presented as a core factor: "It drives to the heart of the New Economy". Here the authors are affirming, in turn, that the two causal factors involved in these long-term developments are fundamental technological changes, on one hand, and globalisation or "openness", on the other. "These two meta-developments lead to increasing integration and prosperity worldwide, which lays the groundwork for a more open global society and a civilisation of civilisations in the $21^{\text {st }}$ century".

A New Economy concept is only touched upon at the text's margins. The authors refer more frequently to the notion of a "Network Economy", an idea first been suggested by K. Kelly, chief editor of Wired, and which constitutes, in his opinion, an essential element of the New Economy. In its content and context, we see in this text a stereotypical manifestation of New Economy radicalism. Instead of developing a scenario, the text primarily offers an optimistic and utopian vision of the period between 1980 and 2020: "We should stop being so incredulous. Let's open ourselves up to these possibilities, sit down, and find out about the future history of the world."

The future-looking and imaginary scenario conveyed by The Long Boom has a starting point or core thesis that is, from the very outset, strongly geared towards a utopian outlook, involving a virtuous economy that enjoys strong growth for an almost indefinite period of time. This virtuous vision of the economy becomes possible if one has an optimistic view of the new technologies' effects, as well as the sentiment that these effects can trigger a certain number of other cultural, social or geopolitical phenomena.

One example of an approach that is utopian but not visionary, and therefore more technical in nature, is provided by Ed Yardeni, often introduced as a New Economy "guru". Chief economist at Deutsche Morgan Grenfell, Yardeni regularly publishes an Internet column that is simply entitled "New Economy". In the diverse and numerous texts that Yardeni publishes online, he sometimes uses paradigm concept (i.e., new vs. old paradigms). 
The language Yardeni uses is not as future-oriented and visionary as Schwartz and Leyden's. The outlook is that of an economist who does not spill over into adjacent domains, such a sociology, political sciences, etc. Yardeni's articles include technical aspects, references to economic theory, and many charts containing U.S. economy macroeconomic indicators. This is what distinguishes him from more literary or visionary depictions of the New Economy. However, the radical nature of some of the pronouncements he makes leads us to classify him as a proponent of the New Economy, in the third sense of the term.

As a proponent of New Economy theses, it is hardly surprising to discover that E. Yardeni adheres from the very outset to the idea that the new technologies have been a catalyst for large scale and definitive quantum leaps in the economic sphere. "The high-tech revolution is the main factor enhancing the relevance of a model that is based on perfect competition as a way of explaining current performances and forecasting future performances of the U.S. economy and of the world economy." He stresses the role of the Internet, of computers, and more generally, of ICT.

He clearly announces that his economic outlook is global in nature: "[the Old School] don't believe that major structural changes in the U.S. and global economies following the end of the Cold War reduce the likelihood and severity of cyclical upturns in inflation. Currently, the pessimists predict that tight labour markets will boost wage and price inflation, forcing the Federal Reserve to tighten credit. These low-tech economists just don't get it: The world has changed dramatically and it will continue to do so at an even faster pace as we move into the next century." (16)

Here, we are clearly again running into the usual statements on how growth and productivity have been under-evaluated: "We are underestimating growth and productivity and overestimating inflation... My view of the world is working better much better than the business cycle promoted by economists who disparage the so-called New Paradigm" (Ibid.).

This is a very significant aspect of Yardeni's theses, one that, whether explicitly or not, we feel plays a central role in the New Economy concept. It is the idea of the death of macroeconomics: "The triumph of capitalism also marked the triumph of microeconomics over macroeconomics... The new "in" model is Perfect Competition. Out are Keynesian, monetarist, and other macro models. Ironically, the New Paradigm is actually an old model that was explored by the great economist Alfred Marshall... in 1890 ! " (Ibid.).

This announced death of macroeconomics is coherent with the notion of a perfect economy - an idea that lies at the very heart of the New Economy. If growth is in some way or the other spontaneously perfect, this implies that an economy is no longer constrained by the interactions between its various aggregates, or by the need for global adjustments. A dynamic invisible hand supposedly ensures growth without disequilibrium. The Federal Reserve Bank's regulating interventions would therefore never again have a reason to exist. And with this putative end of macroeconomics, monetary and budgetary policies would be automatically co-ordinated; and economic analysis reduced to a study of market adjustments.

In fact, inasmuch as economic policy can only construed in terms of an economy's general interdependencies and overall regulations, what Yardeni is in fact announcing is the end of economics. In essence, he is joining the chorus of those who believe in the predominance of microeconomics over macroeconomics. 
Does the end of the Cold War, and the emergence of the New Economy, denote the ultimate triumph of capitalism? Yardeni is circumspect on this topic, and follows an original approach in his discussions of it. In his opinion, "Capitalism is still in conflict with an old adversary, namely corruption." (Ibid.) He continues along these lines by stating: "Could it be that there are only two alternative economic systems and nothing else: Capitalism and Corruption? Communism was just a corrupt system with an ideological disguise. The ideology collapsed, but corruption is as widespread as ever on this planet." (Ibid.)

We see here that the New Economy is more than a mere macroeconomic phenomenon. Certain analysts highlight and focus their attentions on the microeconomic changes that have taken place, but Yardeni in his own way prefers to stress the idea of competition. One of the issues that he discusses involves the changes in economic laws that are associated with the new technologies. All in all, special attention is paid within the context of the New Economy to various phenomena that are not in fact radically new, such as externalities or increasing returns of adoption.

Within this framework, it is natural that the spotlight has been cast upon the "new" economic laws, i.e., those that apply to information in its construction as a specific good. (17) Here again, we are not dealing with a particularly new theme in the field of economics. (18) The role that is fulfilled by this type of good creates new structural conditions whose impact can be considered as being something specific, or exceptional in terms of its size ?. Two American economists, H. Varian and C. Shapiro, have devoted a book to the study of the rules that apply in an information economy. (19) Their view is that although technologies change, economic laws do not. In their opinion, the notion of a New Economy should be referred to explain the changing nature of certain goods or economic activities, and correlatively, of jobs and profits. The goods that are produced by the agricultural or manufacturing sectors occupy a relatively declining position in the whole; they are being replaced by informational, communication-oriented and leisure goods. Yet even though there is something new in the way in which economic activities are being structured, this is not mean, according to these two economists, that we should be evoking the New Economy concept when analysing at a company or sectorial level. After all, at these levels, no new basic economic laws have been born. On the other hand, they seem to suggest that, inasmuch as technology can drive a healthy type of growth, the New Economy concept is applicable at a macroeconomic level.

For the "radical" proponents of the New Economy, macroeconomic performances are the specific consequences of ICT and of its immediate effects on productivity. They insist on the revolutionary nature of these changes. In their opinion, the advent of strong non-inflationary growth associated with a significant degree of productivity, that is, the type of growth that the United States seems to have experienced since the early 1990s, is no accident. Moreover, this growth may continue to be sustainable for some time to come. As for the question of whether the turbulence and changes that we have been witnessing are the temporary side effects of the transition to a new type of society or the permanent manifestations of a new economic system, the New Economy's proponents opt for the second solution. For this reason, "the challenge today is to learn how to manage and guide events in an era of constant and sustained innovation and adaptation." They also stress that in their opinion, the statistic apparatus is not adapted to the developed societies' new characteristics.

We can observe that globalisation is being seen here as one of the New Economy's core attributes, whereas in the other conceptions, this theme is either absent (see the first meaning in our typology above), or else not deemed to be particularly significant. This is primarily explained by another, previously unmentioned aspect, which is the neo-liberal nature of the New Economy. According to its proponents, it is the market economy and the existence of competition that have caused (i) pressure to be exerted on 
prices, and thus lead to a continued control over inflation, and (ii) a regime that is marked by the permanence of innovation.

Here are a few observations on the distinctions that we suggest making between the three "core" uses of the New Economy concept:

- First of all, these three possible meanings of the New Economy concept express three different attitudes: an empirical attitude for the first; a more interpretative yet cautious attitude for the second; and a frankly optimistic attitude for the third. We thus note that the order of presentation mirrors to a certain extent the meanings' rising optimism ranking.

- The confusion or vagueness that surrounds this New Economy concept stems from the fact that these three orientations are not independent from one another. They overlap and in fact interconnect: advances in ICT explain and justify the optimism of New Economy radicals, and also are part of the specific characteristics that appeal to New Economy "moderates". The "astounding" macroeconomic performances are what justify the significance that the New Economists attribute to ICT, which they see as the causal factor behind the quantum leaps that they highlight. This is one of the reasons why the attitude they display is just as important in describing the three conceptions of the New Economy, and in distinguishing between them, as the actual substance of the theses they offer.

- With the exception of a "sectorial" conception of the New Economy (which we consider to be based on trivial principles, even if its technical application can sometimes cause a number of problems) (20), we have retained two of these fundamental approaches. On one hand, the new economy (lowercase letters), which is the way in which we would describe the American economy, referring to the fact that this is where ICT has been developed, and where its economic specificity has become an issue. On the other hand, the $\underline{\boldsymbol{N}}$ ew $\underline{\boldsymbol{E}}$ conomy (uppercase letters), which is applied to the American economy to signify the fact that it is ICT that has determined new characteristics of growth, and the new global trends, that constitute an irreversible break with the preceding period. The idea of a new economy should be understood in its most mundane sense, that is to say, as a topic of discussion. The concept of a New Economy describes a new economic model, with characteristics that are specific and capable of being defined. People no longer speak of $a$ new economy, but of the New Economy. (21) It is to this original, "strong" (or radical) meaning that we will be referring for the rest of this paper.

\section{A critical examination of radical New Economy theses}

Before discussing the relevancy of the New Economy concept, and of the theses that it conveys, we need to deal with a certain number of issues that are directly derived from the very core of the New Economy thesis:

- Have the U.S. economy's performances during the 1990s been truly exceptional in nature?

- How can we describe the way in which productivity has changed? Can these changes be measured? What do the figures show? 
- To what extent can we talk about a quantum leap in the attributes of the U.S. economy? To what degree has it evolved original characteristics?

- More specifically, can we affirm that there has been a change in certain economic laws?

- Does ICT constitute the factor that determines, drives or structures the U.S. economy nowadays? Is it an explanatory factor for productivity gains?

- Is this type of growth sustainable? Can current trends be extrapolated?

We will be dealing with those topics that we feel are particularly important for the themes being explored in the present study. We will neither delve into the question of whether current growth is sustainable, nor into the various justifications for the idea that the U.S. economy has experienced a radical break with the past. We will conclude this section by highlighting the fundamentally utopian nature of the radical New Economy conception.

\section{Did the U.S. economy experience exceptional performances during the 1990s?}

We are now going to present a certain number of statistical findings, and will discuss their origins, attributes and significance in the section that follows.

\section{The virtuous growth of the 1990s}

There is no doubt but that the U.S. economy's current expansion phase is remarkable in terms of its duration. The United States' previous record post-war period of expansion had lasted for 34 quarters. The current growth phase, which started in March 1991, reached 35 quarters in 1Q 2000. This is a historical record. During 2Q 2000, the GDP growth rate, in volume, was estimated to have reached an annual rhythm of $5.2 \%$ (after taking seasonal fluctuations into account). This is an even faster pace than the preceding quarter's $4.8 \%$. (22) The third quarter is also starting at a rapid pace. For all of 1999, GDP grew by $4.2 \%$ (after $4.3 \%$ in 1998). Despite the extremely advanced stage of this particular phase of the growth cycle, the U.S. economy has manifested a great deal of dynamism.

\section{[Figures $1 \& 2$, next page]}

Consumption has been slowing down. In 2Q 2000, it has been advancing at an annual rhythm of $3 \%$, whereas during the first semester it grew at a record rate of $7.6 \%$ (the highest increase in 17 years). 
Figure 1

\section{Percent changes in real GDP (chained 1996 \$)}

$D$ ata source : B.E.A.

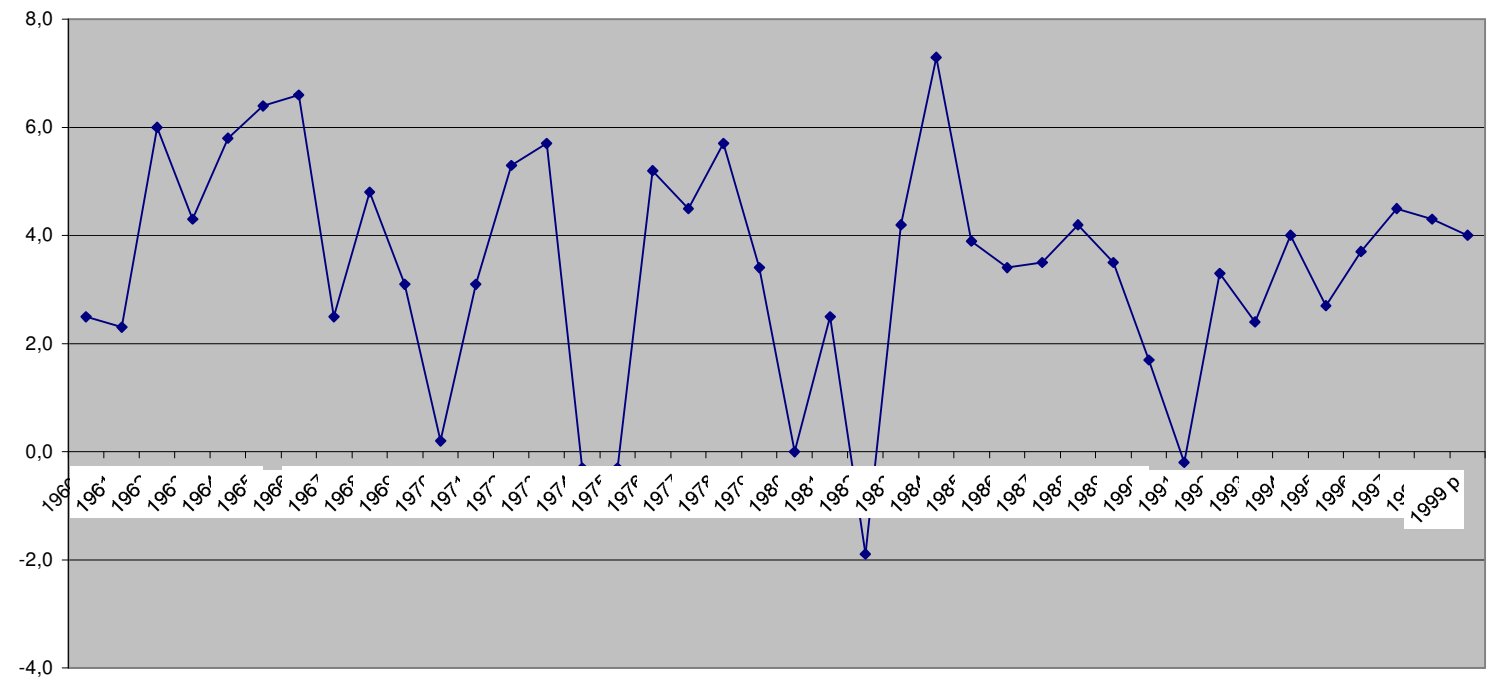

Figure 2

\section{Percent annual changes in quarter real GDP} (chained 1996 dollars)

Data source: BEA

(with polynomial trendline)

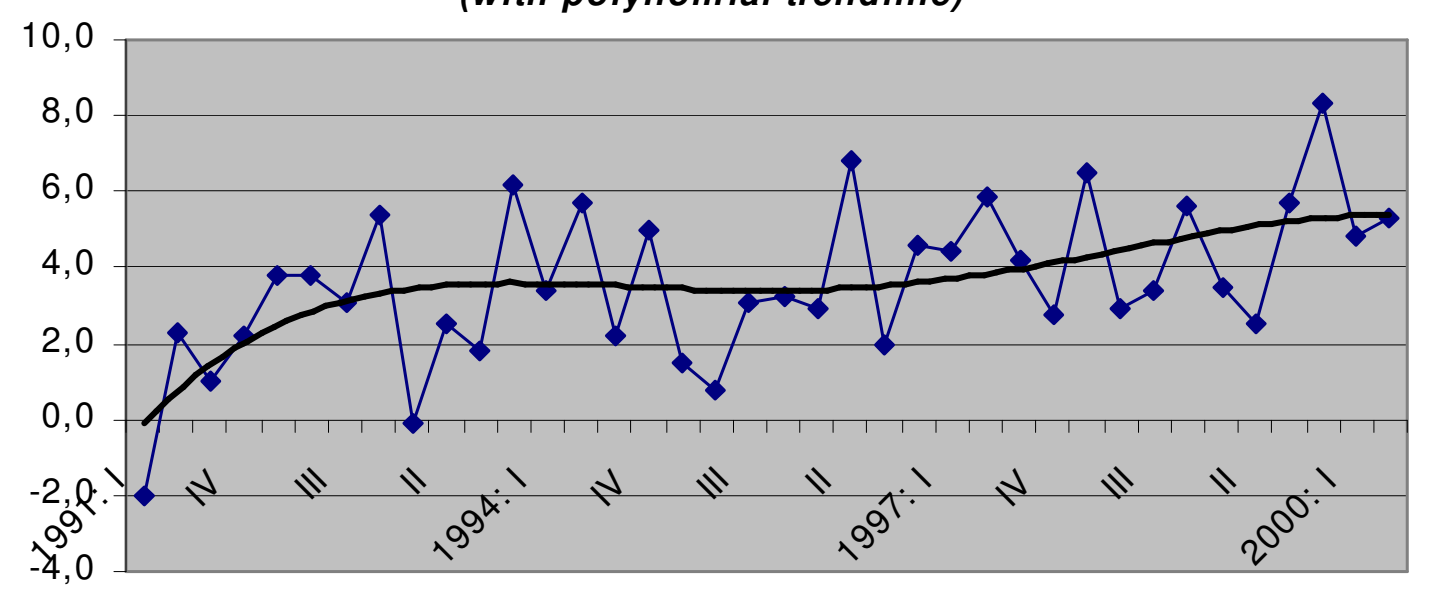


On the other hand, investment has been progressing at an annual rate of $21 \%$, whereas its growth rate during the first quarter was a relatively low $5.1 \%$.

Between October 1999 and February 2000, the unemployment rate oscillated between $4.1 \%$ and $4.0 \%$. It remained at $4.1 \%$ in March 2000, and is at its lowest level since 1970.

[Figures 3,4 \& 5, pages $15 \& 16]$

Since January 1993, when the unemployment rate started to drop after having reached $7.5 \%$ in 1992 (its highest level since 1984), the U.S. economy has created 20 million new jobs. The ratio of people over the age of 16 who hold a job versus the total population over the age of 16 is at a historical maximum of $64,3 \%$. During the 1950 s and 1960 s, this rate was around $57 \%$. (23) The drop in the unemployment rate between 1992 and November 1999 benefited people with a high school diploma as much if not more than it did college graduates (source: Bureau of Labour Statistics, Household Survey).

During 1Q 2000, the Consumer Price Index grew at an annual rate of $3.5 \%$, whereas prices had risen by $1.6 \%$ in 1999, and by $0.9 \%$ in 1998 (Figure 6 below). The sudden increase in imported crude oil prices from early 1999 onwards seems to be the explanation for this abrupt variation. However, the same type of variation has been manifested in the chained GDP Price index (which went from $1 \%$ in 1998 to $1.5 \% 1999$ and $3 \%$ in 1Q 2000). Chain-type price index of gross domestic purchases excluding food and energy reached an annual rate of 2.25\% during 1Q and 2Q 2000, against $1.5 \%$ for all of 1999.

Figure 6

\section{CPI-U 12-month changes, 1990 to present}

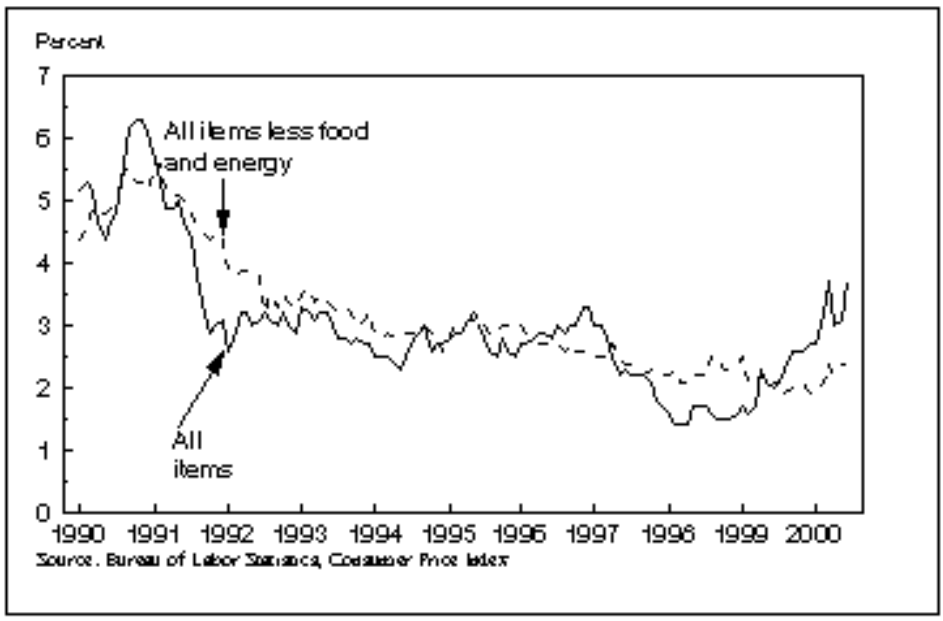

Household consumption and (physical) capital spending (including but not limited to housing) has played an important role in this expansion. For the past few years, the annual growth rate of these two categories has been higher than the GDP growth rate. Exports have advanced at a significantly lower pace. 
We have just examined the favourable performances of U.S. economy - what we can call its "happy face". We should now discuss the exceptional nature of these performances. This empirical discussion will involve an attempt to relativise these performance so as to highlight the U.S. economy's "sad face", i.e., present its more negative aspects. As such, we will continue to deal with U.S. economy's "ostensible" performances.

\section{The historical and geographical relativity of the U.S. economy' sperformances}

The macroeconomic performances of the American economy, in comparative modern economic historical terms, do not have the extraordinary character that the New Economists attribute to them. Between 1944 and 1968, the unemployment rate averaged $4.7 \%$, the inflation rate $3 \%$. In 1966, these two rates were $3.8 \%$ and $2.9 \%$, respectively. In 1952, they were no higher than $3 \%$ and $1.9 \%$. Yet the unemployment rate in April 2000 was $4.1 \%$, and the inflation rate for the year 1999 was $1.6 \%$.

The average annual growth rate over the 1991-1999 period has been 3.6 \%. Between 1959 and 1973, this was $4.5 \%$. (24) Between late 1982 and 1990, it was almost $4 \%$ (more than 3.95 to be precise).

The performances that were observed during the 1990s are clearly something that is worthy of admiration. However, in historical terms, they do not have exceptional character or track record that certain people claim (except of course for the fact that the present growth phase, already the longest in history, is still running).

Nor are these performances particularly exceptional on a long-term international comparative basis. The average U.S. annual growth rate between 1989 and 1998 was $2.5 \%$, that is, about the same as in Germany, and just slightly more than in Japan (which was at almost $2 \%$ ). Over the same period, per capita GDP growth was $1.6 \%$ in United States, i.e., lower than in Germany (1.9\%) and about the same as in Japan. As for the average productivity of labour (GDP per employee), the level has continued to be higher in the United States than elsewhere, but over the decade under study, its growth rate was slower in the U.S. than in Japan $(1.3 \%)$ or in Germany $(2.5 \%)$. We also note, not without a sense of irony, that in 1999 China recorded a $6.6 \%$ growth rate, and an inflation rate of $1.5 \%$ (IMF figures) thus relativising the American economy's performances during that same year $(4.2 \%$ and $1.6 \%$ respectively).

\section{The downside of the U.S. economy: worsening inequality, and private and public deficits}

Is the United States' current growth a truly virtuous phenomenon? Is it not the case rather that several of these macroeconomic performances are trees that hide the forest? Behind these aggregates, should we not be focusing on the significant disparities that continue to plague the U.S., and on the inequalities that cast a shadow on any idyllic presentation of this new growth? 
Figure 3

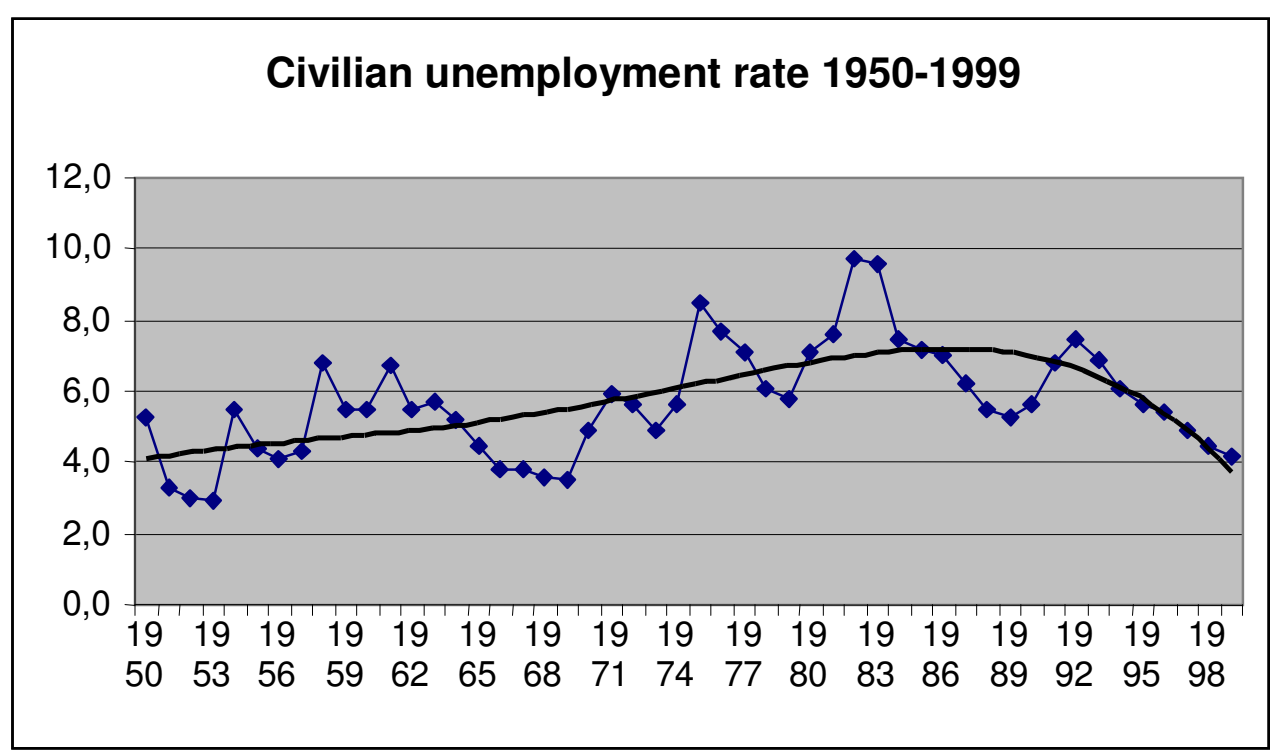

Figure 4

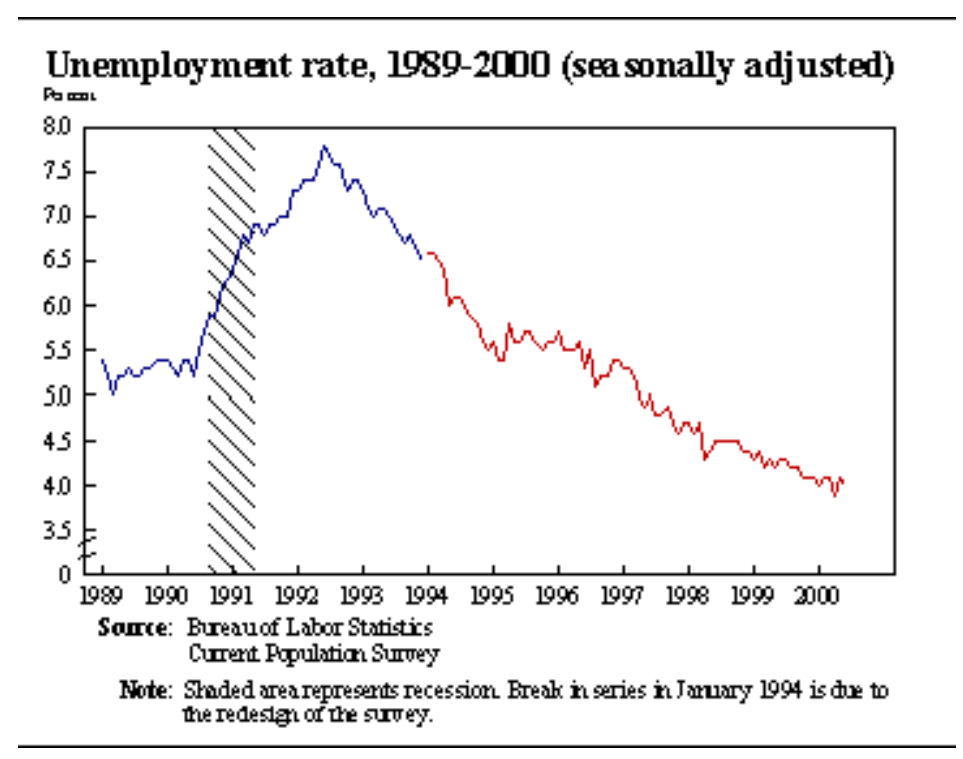




\section{Figure 5}

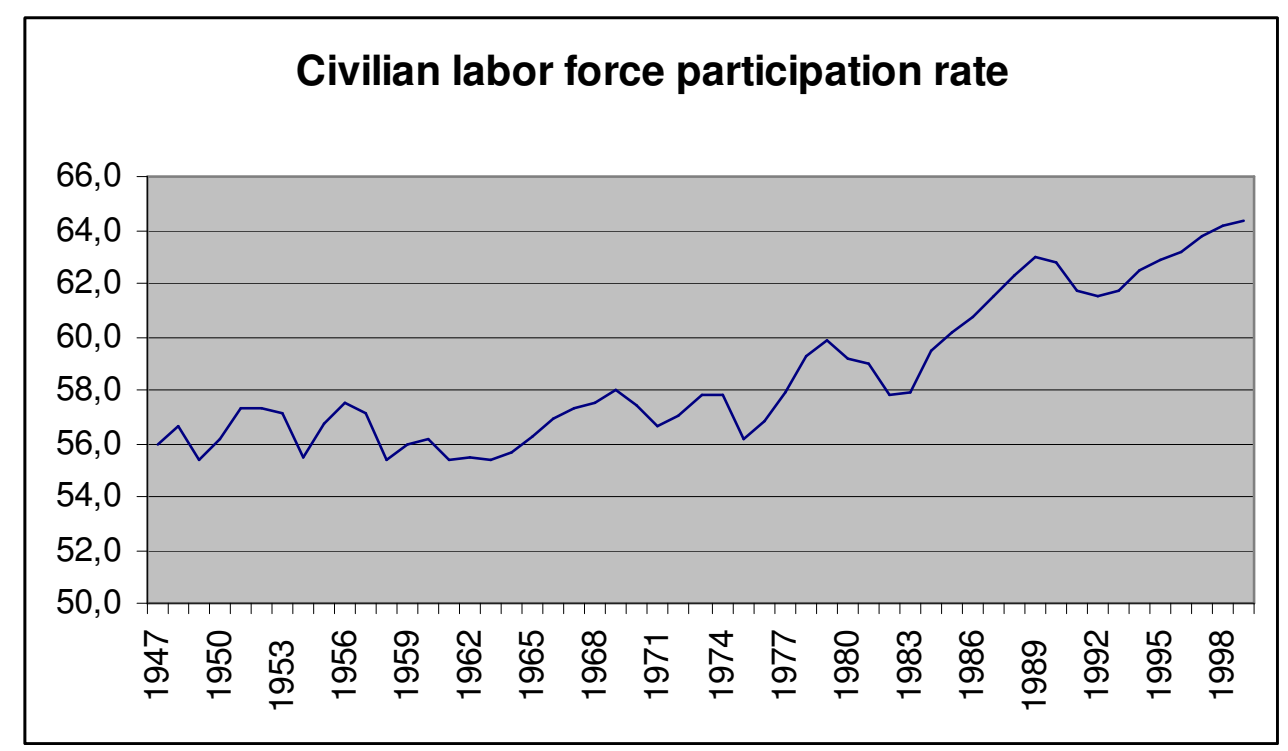

Data source : Economic Report of the President 2000

Income-related inequalities are not only significant, but are getting worse. At the bottom of the scale, one American in 10 had a lower income in 1999 than in 1977. (25) At the same time, the middle class, which concerns six Americans in 10, saw incomes rise by $8 \%$ over 1977 levels, an average annual growth of $0.3 \%$ over these 22 years. At the top of the scale, the top $20 \%$ of all Americans earners received an income that is $43 \%$ higher than in 1977. And at the very summit, a category that concerns one American in 10, income has grown by $115 \%$ over this period. In 1999, U.S. income differentials were the highest since 1945. The richest $20 \%$ of the population earned 9 times more than the poorest $20 \%$. In Japan, this factor is 4 to 1 , and in Germany it is 6 to 1 . The poorest $20 \%$ of the Japanese population have a standard of living that is $50 \%$ higher than the $20 \%$ poorest Americans. (26).

Although employment levels have risen significantly, their quality seems to have deteriorated. This is firstly a result of the job losses that are associated with restructuring operations, and with the "rotations" that have lead to fired employees being "poured" into firms and sectors where wages are lower. According to Anne-Cécile Robert (27), a new category of "pauperised workers" has appeared: of the 38 million Americans who live below the poverty line, 22 million have a job or are part of a family in which another member else has a job. The increase in part-time labour should also be mentioned, as such work is less well paid. This represents $18 \%$ of total employment.

Though there has been a diminution in the unemployment rate, there has also been an increase in the number of hours worked. Between 1967 and 1982, average annual working hours for "entry age" employees (between 25 and 54 years old) dropped from 1975 to 1840 hours. Since 1982, this trend has been reversed. In 1997, average annual working hours in the United States reached 1966 hours, an increase of $4 \%$ since 1983 . This runs contrary to a worldwide trend towards the stabilisation, or even decrease, of time at work. (28) 

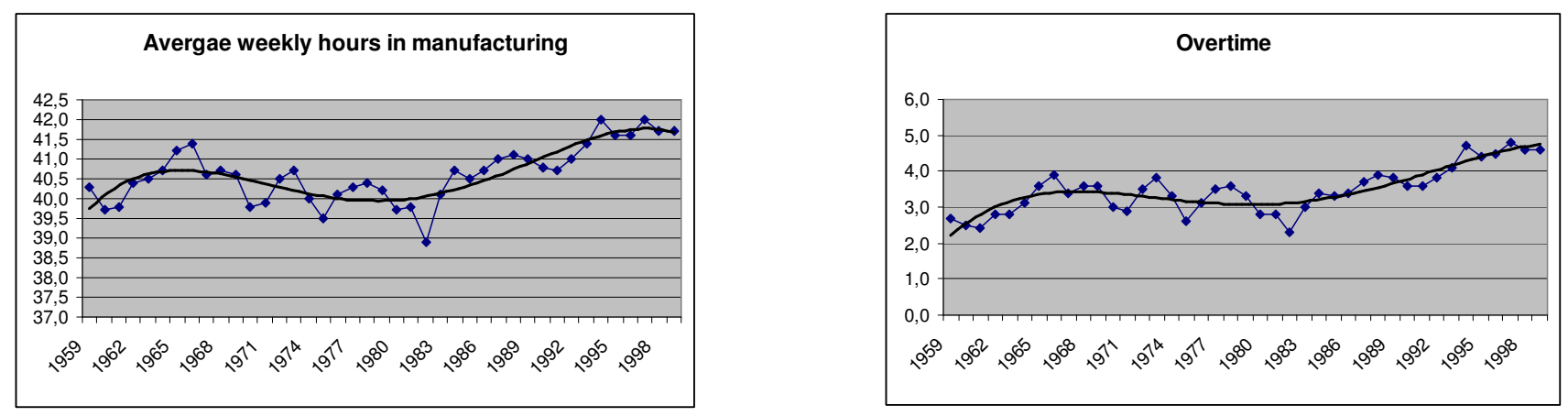

Source : BLS ; with polynomial trendlines

At a purely macroeconomic level, we cannot neglect that alongside certain beneficial trends, there have been at least two others that have increased the American economy's fragility: the trade deficit on one hand, and the rise in total debt on the other. Certain analysts believe that these two elements have increased the probability of a speculative bubble bursting; and they fear the fallout. This also explains the monetary authorities' extreme caution (though some would call it an accommodative stance, and others laxity).

P. Blanqué has noted that "if the current-account deficit continues to rise at an annual rate of 200 billion dollars; with average nominal GDP growth of $5.5 \%$ (the average for the past 10 years); and an interest rate of $5 \%$ (the cost of servicing the debt) - the net external debt of the United States could reach nearly $30 \%$ of GDP." (29) Moreover, with 7\% interest rates and an annual deficit of around 300 billion dollars, the external debt would even attain $70 \%$ of GDP!

Furthermore, according to same source, private debt (ca. 11,000 billion dollars) represents nearly $130 \%$ of GDP. Households' proportion in this has been growing at $8.8 \%$ per annum, and companies' at $10 \%$. Given the low level of inflation, "debt is exploding in real terms".

\section{Another imbalance: the excessive increase in asset prices}

Has a speculative bubble been formed?

The aforementioned trends have taken place against a backdrop of sustained share price increases, criticised by Alan Greenspan as an incarnation of "irrational exuberance". The Standard \& Poor's 500 price index of ordinary shares rose by a factor of 4 between 1990 and 1998 - and then at a rhythm of $20 \%$ between 1995 and 1999. We are witnessing an asset price inflation that is best diagnosed as a financial bubble. Some of these prices no longer reflect U.S. companies' ability to create profits. The demand for them is based less on their profits outlook than on anticipated future share prices. A cumulative and speculative process is up and running. The so-called "Internet" securities are the best example of this - and in fact, are the very symbol of the process. The market valuation of firms who have never turned a profit has reached astronomical levels, reflecting the role that speculation now plays in the formation of stock prices. We are witnessing a wealth effect that has been a prime support for the rise in consumption. 
A few market corrections have occurred, without any real stock market crash having taking place (the present article being written in July 2000). It is true that this stock market exuberance seems to have calmed down to a certain extent.

The aforementioned inequalities also abound with respect to people's shareholdings. L. Browne quotes 1999 statistical studies showing that: (i) $54 \%$ of all shares are owned by the $6 \%$ of all American families who have annual revenues over $\$ 100,000$, and (ii) $80 \%$ of the stock market gains recorded between 1989 and 1997 benefited the richest $10 \%$ of all American families.

The household savings rate has dropped: "Leveraging their stock portfolio valuation, households are now selling securities to finance their consumption, and even more importantly, have been increasing their indebtedness." (P. Blanqué). Finally, it has been observed that "the household savings rate has been decreasing in the same proportions as share values have been rising... For several years, the less households have saved, the more they have increased their wealth, on paper at least." (Ibid.) The stock market is less a reflection of the North American economy's situation than one of the causes of its growth, and of the unpredictable nature thereof.

\section{What about changes in productivity?}

The significance of productivity gains is at the heart of any discussion on the New Economy. First of all, this is because the issue is a strategic one, in that it helps us to assess the potential for non-inflationary growth. Secondly, even before the economy began to recover in 1991, and as a result of the productivity slowdown that had preceded it (and the search for its explanation), the issue of productivity had already become the subject of heated debate. More specifically, the aforementioned Solow Paradox had already captured many people's attention.

Radical New Economists have lent to this debate a polemical tone by affirming from the very beginning that productivity has been inaccurately measured, and that it is higher than people believe. They define the problem in a form that is impossible to contest inasmuch they refuse the information conveyed by official statistics.

We are going to deal with the technical aspects of this debate inasmuch as the American administration has indeed made great efforts to improve the statistical assessment of productivity changes. It is worth focusing on the findings from these statistical revisions, and to see whether the divergences are as significant as the New Economists allege. Once we have got past this debate over statistical techniques, we will then deal with the real issue of changing productivity (as it appears when we use the statistics that are available).

\section{Regarding statistical techniques}

Two very technical aspects should be mentioned first off. First of all, a statistical technique does exist for determining production in volume terms. Until late 1995, in order to estimate growth in volume terms, American statisticians used a fixed or base-year weighted technique that introduced an unfavourable bias against new products. From 1996 onwards, they started using a chained or annually weighted technique. The result is that GDP growth between 1993 and 1995 has been overestimated. For example, in 1993, the pre-revision growth rate was $3.1 \%$. After revision, it was $2.2 \%$. The slowdown observed in 1995 turned out to be even more severe than had been previously estimated. The increased productivity was therefore also overestimated. 
The stakes are not negligible, especially since a Federal Reserve Bank of Kansas City economist has shown that with this new statistical series, the positive trend in productivity gains, a change that dates from 1990 according to the statistical treatment that had been used for the old series, now disappears. Such estimations hardly suit the New Economists' theses!

The other problem resides in the use of either a product or else an income level as a basis for ascertaining productivity. We can in fact evaluate production from the product side or from the income side. However, the productivity evaluations that stem from this method reveal a growing gap between these two findings, starting in the 1990s.

We note that the gap created by these two sources of divergence can be greater than 2 percentage points per annum, which is a significant figure. The "record" was made in 4Q 1994, when the cumulated gap (30) came out at $2.9 \%$ (annual rate). The gap for 1993-94 was $1.2 \%$ : the increase in productivity, evaluated using a fixed base and in income level terms, was $1.9 \%$, whereas using an annual weighting and in product side terms, it was only $0.7 \%$. (31)

\begin{tabular}{|c|c|c|c|c|c|}
\hline & \multicolumn{5}{|c|}{ Productivity rate of growth } \\
\hline & $\begin{array}{c}\text { Base-year weighted } \\
\text { incorme side } \\
\text { a }\end{array}$ & $\begin{array}{c}\text { Base-year weighted } \\
\text { product side } \\
\text { b }\end{array}$ & $\begin{array}{l}\text { Annually weighted } \\
\text { product side } \\
\text { c }\end{array}$ & $\begin{array}{c}\text { Difference } \\
b-a\end{array}$ & $\begin{array}{c}\text { Difference } \\
c-a\end{array}$ \\
\hline Années & & & & & \\
\hline $1990-91$ & 1,5 & 1,3 & 1,2 & $-0,2$ & $-0,3$ \\
\hline 1991-92 & 2,7 & 2,8 & 2,6 & 0,1 & $-0,1$ \\
\hline $1992-93$ & 1,3 & 1,2 & 0,5 & $-0,1$ & $-0,8$ \\
\hline 1993-94 & 1,9 & 1,3 & 0,7 & $-0,6$ & $-1,2$ \\
\hline Trend & & & & & \\
\hline $1990-94$ & 1,8 & 1,6 & 1,2 & $-0,2$ & $-0,6$ \\
\hline
\end{tabular}

\section{Source : Monthly Labor Review, octobre 1995 Part of the Table 2 page 31}

Another relatively classic aspect of this debate over productivity assessment relates to the service sector. This is an older point of discussion, in the sense that it had already been used in reference to the aforementioned productivity slowdown period, with analysts having observed that the drop or slowdown in productivity had been more accentuated in the service rather than in the manufacturing sector. (32) From this point forward, many economists, lead by Zvi Griliches, have suggested that this slowdown was an artefact which resulted from the rise in the service sector's proportion of total production. (33) Griliches identified the sectors in which he felt that productivity was not really measurable, and demonstrated that the proportion of total national production which was represented by these service sectors had become very significant $(70 \%)$.

\section{Changes in productivity}

In terms of the way in which productivity has changed, we have a certain number of observations to make. 
Regarding the average productivity of labour in nonfarm businesses, the increase between early 1991 and mid-1995 reached an average annual rhythm of 2.2\%. (35) This performance during the first five years of the current expansion phase was remarkable for two reasons. Firstly, from 1982 to 1991, the average annual rhythm had been only $1 \%$; although it must be said that this was higher than the average annual increase during the first ten years [1973-1982] of the productivity slowdown (when the rate was $0.6 \%$ ). Secondly, this increase was, relative to the GDP growth rate, the highest that had ever been recorded during any of the post-war expansion phases.

A statistical analysis of the 1960-1995 data reveals four sub-periods and thus three trend reversals (36): 4Q 1972 (shift from an annual rhythm of $2.4 \%$ to $0.6 \%$ ); 1Q 1982 (shift to an annual rhythm of $1 \%$ ); and 4Q 1990 (shift to an annual rhythm of $1.7 \%$ ). (37)

This situation shows the situation as perceived by economic actors and analysts in late 1995-early 1996, at the time when the radical notion of a New Economy beginning to spread. It is important to underline this fact - with the same statistical treatment of the available chain weighted series, covering the same period but starting in late 1995, we obtain a totally different finding: only the 1972-73 trend reversal remains validated.

For the 1996-99 period, we note a significant increase in the average productivity of labour in nonfarm businesses. (38) This changes at an average annual rhythm of $2.9 \%$, whereas the rate had been only $1.5 \%$ during the 1974-95 period - against $2.8 \%$ during the period preceding the slowdown. The historical significance of this move to a higher level, even if the increase is small, should not be underestimated (cf. Figure 9).

\section{Figure 9}

\section{Source : http://economics.about.com/economics/money/library}

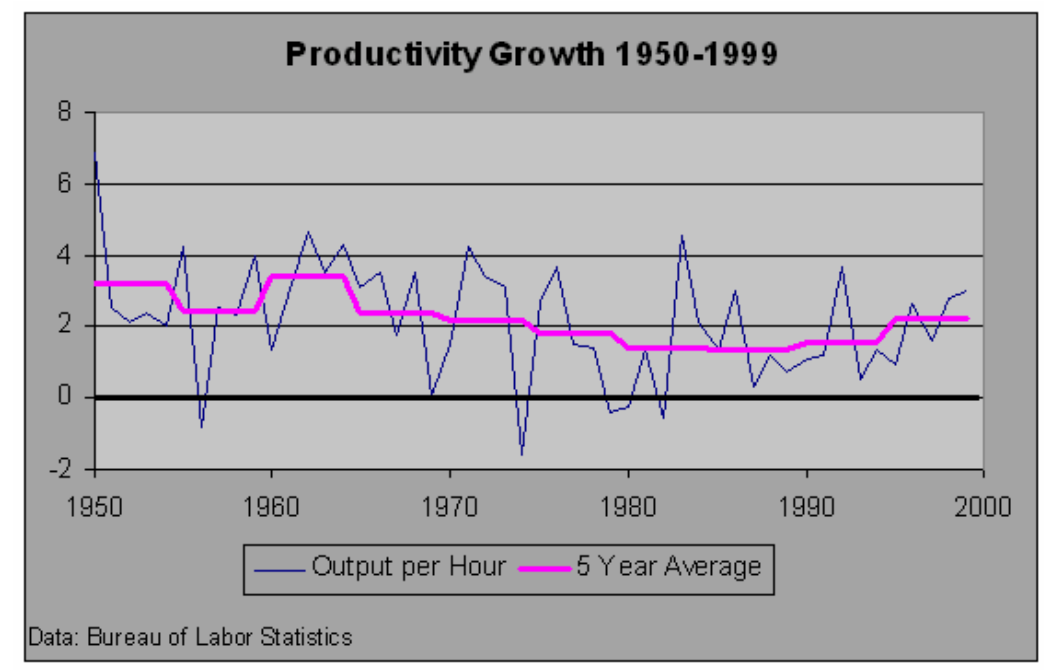

The findings for 1Q 2000 have revealed an increase (expressed in annual rhythm) of $2.4 \%$ in the average productivity of labour, less than 4Q 1999's surprising result (6.9\%). This result is also slightly lower than annual rates of increase in 1999 (3.0 \%) and in 1998 (2.8\%). All things being equal, this may 
indicate a slowdown in the years to come. However, the quarterly findings for the years past show that this indicator has experienced a certain volatility (i.e., with a $0.5 \%$ increase in 2Q 1999 being followed by a rise of $5.0 \%$ in the next quarter). We should also note that the unit cost of labour dropped during two consecutive quarters (- $0.3 \%$ and $-2.9 \%$ during 2Q 1999) before growing again in 1Q $2000(1.6 \%)$.

If we now focus on multifactor productivity, which theoretically constitutes a specific indicator of technical progress, the performances are much less impressive. (40) After the recession of '90-' 91 , which caused multifactor productivity to drop by around $2 \%$ over a period of two years, this measure found itself at the same level in 1992 and 1993 (index values: 100 and 100.1) as in 1987 and 1978-79. In 1997 (the last known figures ${ }^{1}$ ), the index reached a value of 102.7, a historical high. This increase was primarily due to 1996 ( $+1.5 \%$, nearly). The average annual rate of increase between 1991 and 1997 was $0.7 \%$ (our calculation). This figure should be compared with the following (41):

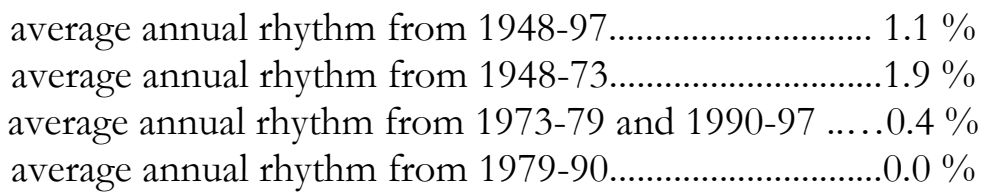

We can observe that the performances which are calculated on the basis of available information reveal a slight increase over the levels achieved during the productivity slowdown.

We are limiting ourselves here to a presentation of the United States' productivity-related performances, such as they appear on the basis of a somewhat cursory statistical analysis. If we were to delve further into this domain, we would need to question the validity and meaning of these findings - an endeavour that we will undertake in the following section. For this reason, we are presenting results that admittedly warrant a very positive assessment of the U.S. economic situation during the 1990s. This legitimises or explains some of the New Economists' theses, wherein these remarkable performances can be imputed to the advent of new technologies. Of course, these economists justify this assertion by pointing out that the 1990s, especially after the deregulation of the telecommunications industry, were clearly an era marked by a veritable technological explosion. They will be particularly apt to dwell on the relationship between these two phenomena, inasmuch as it allows them, to a certain extent, to resolve Solow's famous paradox. We will return to this point later.

\section{Have economic laws changed?}

Are economic cycles about to disappear? Empirically, the cyclical fluctuations of certain variables have diminished, losing part of their volatility. This applies to jobs in manufacturing (with a cyclical volatility of $5 \%$ since 1985, against $9 \%$ between 1960-1980, and $15 \%$ between 1940-1960); to manufacturing capacity utilisation (with a lower cyclical volatility since 1985 than had been observed between 1950-1985); and to investment in manufacturing. Nevertheless, as the organiser of a Symposium on business cycles recently concluded: "Cycles continue to survive, if only through the qualitative continuity of their mechanisms and effects." (42) This means that we should be speaking about a decrease rather than a disappearance of cyclical volatility. (43)

\footnotetext{
1 This paper has been written in july 2000. We now know the 1998 Multifactor productivity (1997-1998: $1.5 \%$ for Private non farm business sector, and $3.1 \%$ for Manufacturing sector).
} 
Has inflation been definitively tamed? If we refer to the usual price indexes, it would appear that inflation is now certainly under control, if not conquered. Still, we should first adjust this impression because of fact that inflation now seems have moved on to the area of stock market assets and financial products. Slightly tongue in cheek, we could in fact aver that the President of the Federal Reserve Bank, who is responsible for monetary policy, manages stock market indexes rather than price indexes. It is true that several of Alan Greenspan's declarations suggest that he pays a great deal of attention to prices on the New York Stock Exchange. In addition, several analysts consider that temporary beneficial factors explain the diminution of inflation pressures, at least since 1996. According to A. Brender, it is the "windfall" from imported disinflation that provides the core explanation for these occurrences.

Does the Philips curve still exist? The combination of low inflation, and of an unemployment rate that is dropping well below the NAIRU (non-accelerating inflation rate of unemployment), has lead the "New Economists" to announce the end of the Philips curve. However, recent research suggests that this construct should be conserved, in that the diminution of the NAIRU can be explained by other contingent factors. (44) For example, R. Gordon, who does not appear to be willing to reject the Philips curve, attributes to a series of beneficial supply shocks the underlying explanation for the positive correlation that has been observed between the changes in the inflation and the unemployment rates since 1991. In his view, the two old supply shocks are constituted by the drop in import and in energy prices, and the two new shocks by the accelerated decline in computer and in health-care prices. As for the NAIRU, Gordon considers that this has dropped even further than many people realise. As for the reasons underlying this drop, his answer is to again invoke the decline in the prices of computers and other exogenous factors.

We are not entirely convinced by this explanation, especially in the framework of a study purporting to criticise the New Economy. Indeed, to defend the Philips curve and the NAIRU, R. Gordon does not hesitate to invoke the existence of shocks, i.e., varied and diverse exogenous factors that are akin to manna fallen from heaven. Moreover, he repeatedly stresses the twin role of accelerated productivity and lower computer prices, that is, the very traits that characterise the New Economy school of thought. And all this to ultimately conclude that "virtually all the progress [from the acceleration in overall productivity growth since 1995] has been concentrated in the durable manufacturing sector, with surprisingly little spillover to the rest of the economy."

\section{The role of ICT}

The central theme of the New Economy in its radical form is the affirmation of the crucial role played by ICT throughout the entire economy. The issues raised thus revolve around the macroeconomic consequences of advances in ICT. Can we infer that ICT drives global growth? Is it the source of productivity gains that are then diffused throughout the economy?

Any assessment of ICT's contribution to increases in productivity first presupposes that we distinguish between the overall (or multifactor) productivity of factors and the average productivity of labour. It is the overall productivity of factors that constitutes the true measure of technical progress, that is, of the improvement in productive combinations. When we evoke the Solow Paradox, this is in principle the type of productivity that we are discussing.

Let's go back to table 2, which presents data compiled by Paul Bauer (op. cit.)

Table 2 


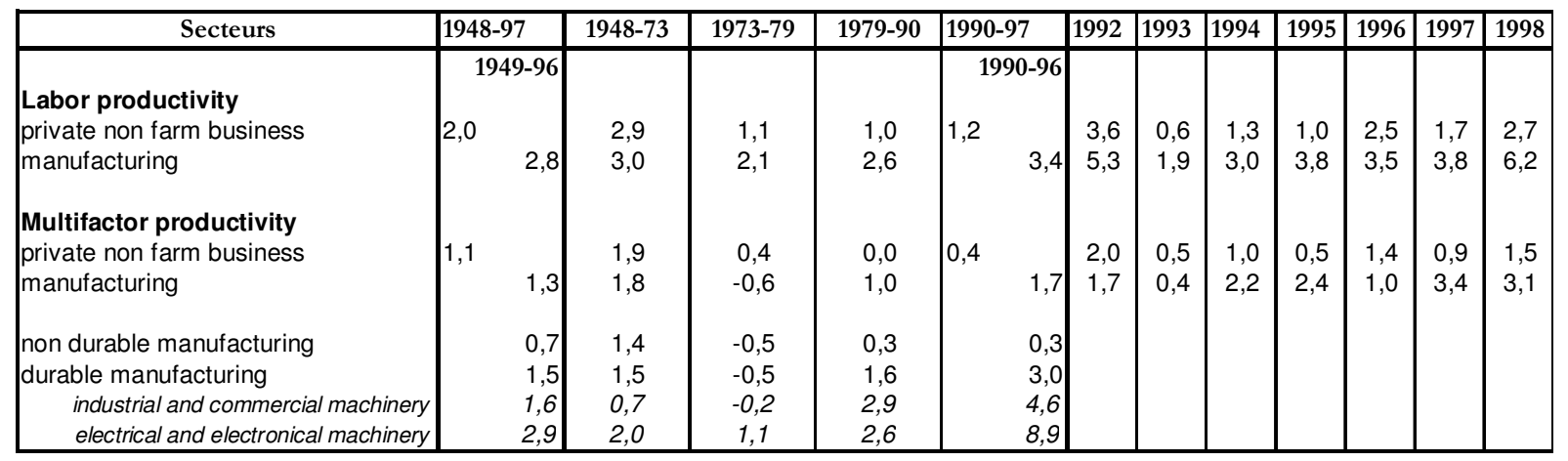

Source : Paul Bauer and BLS, Multifactor productivity trends, 1998

There are at least three observations that we need to make. First of all, for all of the periods or years under study, productivity gains in the manufacturing sectors are higher than the aggregate increase across the entire nonfarm business sector. This is a clear demonstration of the fact that the increased productivity of services (this being the aggregate that has the greatest effect) is lower than the overall sectorial "average". Secondly, within the manufacturing sectors, the performances by those sectors that produce durable goods are always higher than for the non-durable good producing sectors. Finally, and more specifically, the sectors that produce electrical and electronic goods (including computers) are those that always have the highest performances.

There is a great deal that can be learned from breaking these numbers down amongst the various sectors. We could also have quoted other studies (46), but in our opinion, the aforementioned data suffices "to get the message across" with respect to the technical progress that has already taken place, i.e. the technological improvement that has been manifested by the increase in multifactor productivity.

This sectorial analysis allows us to determine where we can find those productivity gains that are a consequence of technological change - hence which sectors are performing well, and should therefore be tracked, basically because they are the source of the overall rise in average productivity. In the end, in terms of the technical progress that has taken place, the overall aggregate figure translates a non-homogenous spread of productivity gains; indeed, a structure that is actually heterogeneous, very concentrated or localised. This would tend to signify that technical innovation takes place wherever computer goods are being produced - but that for the time being, the actual technology that is being used in computing has up until now had little, if anything at all, to do with generic technology. (47) The diffusion of ICT does not generate the externalities, spillovers, improved practices or technological changes that we would have expected. We are not witnessing any contagion of technical progress or innovation through every sector of activity, whether as a result of the influence of ICT, or because of the opportunities that it offers. Sectors that are major new equipment users (such as finance, insurance, property or other services) continue to perform less well than others do. Their contribution to aggregate multifactor productivity is negative. The Solow Paradox, albeit modified and fine-tuned, thus continues to be in effect.

The other issue we need to broach relates to a possible improvement in the average productivity of labour through the intensification of the capital being placed at employees' disposal. An acceleration of this productivity could be the result of an increase in multifactor productivity and/or of an increase in capital per employee. The issue is one of discovering where productivity gains are localised. Now, the 
average productivity of labour seems to have experienced a trend reversal in 1995. (48) Inasmuch as there had not been any interruption in the overall rhythm of technological progress in the United States (49), this can only be explained by an accelerated rate of capital accumulation. This raises a question as to the concentration of this accumulation.

There is no reason why most investments in computers should be concentrated in the sector that is responsible for producing computer goods. We can ultimately assume that the effects of the technical progress that was made in the electronic goods manufacturing sectors were probably manifested through an intensification of capital in the other sectors. In other words, they would have had a certain impact in productivity terms, but not in the form of a specific, multifactor productivity expressing a transformation of the technology being used.

We do indeed observe a significant increase in investments in computers, both in absolute and in relative terms, in the investments of firms belonging to all sectors of activity. Thus computer advances do indeed have an impact on the productive system; however this influence is not conveyed via clustering phenomena or through a generic diffusion of technology. It is manifested by an intensification of the capital being used - without, if we are making the correct interpretation, any major improvement in technology...

All in all, this causal chain provides a good explanation when we introduce into our line of thinking the economic calculations that are made by those firms that are situated at the upstream end of the electronic goods-producing value chain. By perfecting technological processes or improving quality, it is possible, even in a very competitive environment, to lower prices, thus inducing the firms that use these factors to increase their investments. (50) In a recent study, S. Tevlin and K. Whelan demonstrate that two parameters play a crucial role in explaining the 1990s investment boom: accelerated depreciation schedules, and the capital cost of computer materials. The authors conclude that the specific investment-related behaviour that cropped up during the 1990s "resulted from the substantial impact of rapid computer price declines on capital accumulation, and the consequent need for a higher rate of replacement investment" (p.2). As these parameters vary greatly from one sector to another, it is necessary to apply an approach that revolves around a sectorial breakdown.

Several recent studies have tried to assess the different sectors' (users or producers of ICT capital goods) contributions to growth, and to the increase (or acceleration) in productivity - be it the average productivity of labour or else multifactor productivity. As an example, we include the findings of Oliner and Sichel's latest study. (51) 
Table 3

\title{
Acceleration in Labor Productivity from 1991-95 to 1996-99*
}

\author{
1. Labor productivity
}

1.05

Contributions from:

2. Information technology capital services per hour .46

3. MFP in computer production and computer-related .26 semiconductor production

4. Other capital services per hour

5. Labor quality

.04

6. MFP in other semiconductor production

7. MFP in other nonfarm business

\section{* Percentage points per year.}

Note: Detail may not sum to totals due to rounding.

Source: S. D. Oliner et D. E. Sichel, op. cit.

Above and beyond the differences that are due to methodology variations and/or to the data being used and possibly reprocessed, we observe a certain convergence. (52)

R. Gordon stands out somewhat because of his assertion, in a paper written in 1999 (53), that the various types of technological progress that have been a part of computer hardware production explain in and of themselves all of the improvements in average productivity labour throughout the nonfarm business sector. This analysis is based on data that precedes another revision of national statistics that took place back in October 1999. According to S.D. Oliner and D. E. Sichel, a new calculation undertaken by R. Gordon using the new data has lead him to modify his conclusions and to offer an assessment of the aforementioned contributions that is not incompatible with their own.

This would also seem to suggest that overall average productivity gains are no absolute guarantee for an absence of bottlenecks, and that the potential for growth is "well spread", that is, exists everywhere. Any argument that uses the aggregate increase in productivity gains as an explanation for the absence of inflationary pressures is thus eminently questionable.

The other issue is a more profound one, and requires that leaving the technical domain that we have been concentrating on. If overall productivity gains are concentrated in the ICT-related material goods producing sector, this implies that the improvements or optimisations that these goods are supposed to engender will not be manifested outside of their own production system. Yet this is contrary to the New Economy thesis.

In other words, radical New Economists have a vision of today's economy that consists of generalising a modus operandi, and behaviour, that is endemic to Silicon Valley. This can be explained in behavioural terms: they project beyond the borders of the relevant professional and geographic sphere performances that only apply in one particular sector of activity. (54) 
Note that the validity of Zvi Griliches' arguments is not diminished by this type of analysis, involving as it does a situation that is diametrically opposed to the productivity slowdown. Quite the contrary, we again find a gap between the manufacturing and service sectors, a schism that Englander has also emphasised. The service sectors are always the areas within which productivity gains appear weaker. We can in fact further specify this by concentrating on performances in the FIRE (Finance, Insurance and Real Estate) sector, as compiled by D. Jorgensen and K.Stiroh. To do this, we can compare these performances with those that have been achieved by sectors featuring a similar rate of value-added growth (55):

Table 4

\begin{tabular}{|c|c|c|c|c|c|c|c|}
\hline & \multirow[t]{2}{*}{ Output Growth } & \multicolumn{4}{|c|}{ Contributions of Inputs } & \multirow[t]{2}{*}{ MFP } & \multirow[t]{2}{*}{ ALP Growth } \\
\hline & & Capital & Labor & Energy & Materials & & \\
\hline F.I.R.E. & 3.423 & 1.139 & 0.940 & -0.001 & 1.521 & -0.176 & 0.664 \\
\hline Electric Utilities & 3,219 & 1.006 & 0.196 & 0.673 & 0.829 & 0.515 & 2.522 \\
\hline Motor Vehicles & 3.611 & 0.277 & 0.294 & 0.020 & 2.778 & 0.242 & 2.279 \\
\hline Chemical Products & 3.471 & 0.740 & 0.474 & 0.089 & 1.585 & 0.584 & 2.018 \\
\hline $\begin{array}{r}\text { Electronic and Electric } \\
\text { Equipment }\end{array}$ & 5.457 & 0.760 & 0.649 & 0.034 & 2.038 & 1.975 & 4.078 \\
\hline
\end{tabular}

The contribution of the increase in capital and labour factors to this sector's growth is the highest of any of the sectors that make up this small sample, even higher than for Electronic and Electric Equipment. The contribution of supplied materials is comparable in this sector and in the other sectors. However, the contribution of multifactor productivity is negative, and this weighs on the average productivity of labour, which is lower here than in any other sector in the U.S. economy (after Government Enterprises).

\section{The New Economy as a utopia}

A New Economy radical paints a picture of the U.S. economy that is both simplified and idealised. Our analysis of the U.S. economy's situation, although limited to just a few indicators, involves a much higher level of nuance, thereby modifying the New Economist representation.

There is no doubt but that, at least with respect to the productivity issues that it raises, the New Economist position seems to have been substantiated by the facts, insofar as a certain number of revisions have indeed been introduced. Yet several of these revisions clash with the New Economists' views. For example, the introduction of chained indexes in 1996 has revealed an over-estimation of productivity (and not an under-evaluation), such that the quantum leap that many believe to have taken place in 1990 disappears, with only the 1973 trend reversal remaining.

In sum, the majority of this New Economy construct either turns on propositions that are impossible to contradict, and which cannot be argued scientifically (estimation of productivity gains, disappearance of cycles); or else on propositions that, once they are examined, appear to contradict the facts (i.e., the role of ICT). 
We believe that this New Economy school of thought should therefore be defined as being utopian in nature and in status.

According to R. Ruyer (56), the essence of a utopia resides in the utilisation of a process that he defines as "a mental exercise involving lateral possibilities." A utopia neither seeks to further knowledge, nor to come up with a theory of reality. A utopian mode is an exercise or a game that touches on the real world: "[The utopian] has fun experimenting mentally with the possible outcomes that he/she sees as existing outside of the real world." Utopia is a fiction that "makes people see things in an unexpected light." (57)

A utopian nevertheless purports to be less of a dreamer or an artist, and more of a wise person - even though s/he is not really seeking the truth. According to R. Ruyer, the wise person formulates hypotheses and uses his/her mental experience to arrive at the truth. S/he intends to test and verify his/her vision. The social utopian, on the other hand, "continues to work on a known hypothesis; on a false one; or even on a clearly invalid postulate. This is not because the utopian cultivates errors for their own sake, but because s/he is more interested in expanding consciousness than in seeking the truth."

The New Economy is a utopia in the sense that it is a game involving a particular object, the American economy, and because it purports to study this object's possible evolutions. A substantiation for this games orientation can be found in the New Economy proponents' original position. This attitude consisted of superseding what can be statistically proved; postulating as a basic principle the idea that the real new economy operates outside of statistical series that had been designed under the "old paradigm"; and constructing and inferring the consequences of the causal relationships that are at its core (the validity of which some appear unwilling to discuss frankly). They believe in the existence of a new world, a universe that is impossible to see using available indicators. For them, another reality exists, above and beyond the numbers. New Economy proponents insist on the fact that we are, at the dawn of a new century, about to enter into an era of prosperity. This is indeed a utopia - the vision that is being conjured up revolves around a de-phasing, that is to say, around a distancing from (statistical) appearances; and on a systematisation and projection into the future of this present, albeit invisible, universe.

Take the example of the current debate over the U.S. economy's potential growth rate and "speed limit". This question has been at the heart of the debate that has been brought on as a result of the positions that the New Economists have been taking. First of all, it stems from the fact that the extent of future growth should be considered as one of the system's main challenge. In addition, knowing the maximal growth rate that the American economy can sustain without causing any renewal of inflation constitutes the technical starting point for discussing potential implementation policies. People usually accept that this potential non-inflationary growth rate is around 2 to $2.5 \%$ per annum (closer to $2 \%$ ) - this being the rate at which unemployment remains stable, and where no inflationary pressure arises. Many affirm that the natural employment rate that corresponds to this growth rate (58) is around $5.5 \%$ (59). In reality, the non-inflationary unemployment rate in United States has dropped below this $5.5 \%$ mark, and has now reached the $4.1 \%$ mark.

Underlying this potential growth rate calculation is the idea that this figure should be equal, by definition and algebraically, to the sum of the workforce's potential growth rate and the potential growth rate of productivity. If both the workforce and productivity have a growth rate of $1 \%$ per annum (corresponding to that which had been observed during the early 1990s), this would justify a potential growth rate of $2 \%$. However, the New Economists' argument basically consists of postulating that: (i) 
rapid technological change means productivity gains of more than $1 \%$ or even $2 \%$, (ii) the work force growth rate exceeds $1 \%$, and (iii) globalisation caps price increases, so that overheating will not cause any inflation to speak of. (60) In incorporating an allegedly "real" value of productivity gains, i.e., a higher value than the one being observed, New Economy proponents are stating that we have to reason using a "real" growth rate which is higher than the actual measured rate.

Yet, as P. Krugman recently wrote in a very explicit article, "if it is the appropriate growth target that we are starting to question, it no longer really matters whether official numbers are accurate." (61) Indeed, productivity and growth measurements are interrelated: if one is over or under-estimated, the other will be too, and to the same extent. And if these two aggregates are interrelated, and biased in the same direction, the under-evaluation of productivity gains no longer constitutes an acceptable argument for setting more ambitious growth targets. In such conditions, postulating an achievable growth rate that is higher than the observed one (under the pretext that productivity has been under-evaluated) is tantamount to mixing up the two scales of measurement (the "true" and the "false"). The reasoning is incoherent.

R. Ruyer has written several excellent pages on what we can call, for lack of a better term, the "ill faith" of the utopians, who often "confuse not only the ranking of the aggregates that are being dealt with, but their size itself ... [they] mix up the aggregates' hierarchy." According to Ruyer, this confusion is one of the "keys to social utopia." We can clearly speculate as to whether this confusion is intentional or not. In any event, it allows us to better understand why technical discussions on the validity of the New Economy's principles can sometimes appear so pointless.

It is difficult to situate the New Economy school of thought in a context, and to make an assessment of it. Texts oscillate between an approach that purports to have scientific intentions (E. Yardeni), and others that are presented in a frankly utopian manner (P. Schwartz and P. Leyden). The less factual they are, and thus the more utopian, the more these New Economy texts distance themselves, in their construction, from scientific argumentation. They come to life through the exploration of "lateral possibilities", which is to say, in a thought process that amplifies "de-phased" visions of reality. They convey a vision of a digital society's economy that is akin to a sort of hermeneutics. It is by using a utopian mode that New Economy proponents wander towards a description of the perfect economy (this being understood as a perfect capitalist economy). Having embarked upon an experience in lateral thinking, they change directions at a certain point, abandoning a realm defined by their reinterpretation of the real world (62) to move on to a description of a new world or perfect universe. This re-creation of the cosmos is manifested in traditional utopian literature by the description of a perfect world, a closed system, of an insular nature. R. Ruyer writes, "utopia is a game because it creates seemingly perfect, self-contained worlds." The perfection of the New Economy, even if this is not what the conceptions' defenders are actually claiming, constitutes one of its intrinsic characteristics, and in our opinion, signifies its utopian nature.

This perfection is not particularly concerned with the perfection of the market, or with an equilibrium and optimum of a neo-liberal and utilitarian economy. Rather, it focuses on the notion of perfect growth, almost entirely lacking in price increases; and featuring full employment plus significant and continual productivity gains (and therefore steady progress over the long run). In this perfect growth, entrepreneurs are able to show initiative; everyone can create their own company and participate in innovation; and constantly rising share prices allow all to enjoy the fruits of a collective dynamic. The market's perfection is to a certain extent the basis for this perfect type of economic growth - and as such, the two phenomena are inseparable. Yet if the utopia of a perfect market mirrors the utopia of the 
individual, of pure rationality, and of equilibrium, the utopia of the New Economy adds a supplementary dimension. This is the macro-dynamics of a progress that is indefinite, that has never experienced a crisis, and which allegedly stems from the advances in ICT that can occur in an environment marked by a freed and deregulated market.

The New Economy translates an extension of market utopia to the dynamics of innovation and technical progress. It is basically more inspired by Schumpeter than by Walras and Palreto - and herein lies its originality. The vision being proposed centres on a society that is undergoing a perpetual flow of changes. Its originality is to have proposed a new neo-liberal utopia, one that involves a "perfectly" growing and highly innovative economy.

\section{What can be said about the non-radical vision of the New Economy?}

Our view is that the New Economy, in the strict sense of the term (i.e., as a radical thesis concerning the virtuousness of a long-term ICT-based expansion in United States), is an inadmissible argument. This is not because the underlying reasoning has been contradicted per se. Rather, the problem stems from the fact that it is impossible for us to put its meanings to any rigorous testing; or to discuss its theses scientifically. As a way of perceiving the real world, the New Economy has a utopian status. Not every text that has been written on the New Economy possesses the same degree of utopianism. But each participates in a school of thought that generally leans towards a utopian approach.

The empirical question that the New Economy tries to answer, i.e., how to describe the economic situation in the United States since March 1991, still needs to be dealt with. In other words, in rejecting the utopian or radical definition of the "New Economy", we have to take the second, more "moderate" stance. Although the quantum leap thesis is questionable, and despite the fact that the radical and even utopian attitudes of several New Economists deserve to be met with a great deal of reserve, we cannot deny the facts. Taken one at a time, the numbers and elements that have been observed are in need of re-evaluation. But globally, the U.S. economy has undeniably demonstrated great dynamism; to such an extent that it would be wrong to do no more than simply criticise the theses that we discuss above.

The burden of proof is shared. Although radical New Economists are not in a position of being able to prove the existence of some quantum leap having caused deep-seated and long-lasting (sustainable) changes to the economy, are other economists (sceptical or moderate ones) able to provide a viable rival explanation?

We need to recognise that no truly alternative explanation exists. In this situation, two attitudes appear appropriate. On one hand, certain economists seem to argue, explicitly or not, in favour of the existence of a certain number of relatively contingent factors or circumstances (or "shocks") whose combined effect could have given birth to the current situation - whose longevity may be shorter than some predict (quite the contrary). We can call this the "miraculous interim period" thesis.

The other attitude is one of indecisiveness, which may be provisional inasmuch as observers can be of the opinion that it is the facts that will decide everything. If the performances of U.S. economy continue in the current vein, and are therefore confirmed, we will have to finally accept that what has in fact occurred is something which is structural in nature. This seems to be the (pragmatic) attitude of Alan Greenspan. The next few quarters will therefore be a test. When we have more points to study along our statistical curves, econometric assessments will help us to confirm trends that, at least for the time being, are invisible, or else tenuous, insofar as they have just got underway. 


\section{The contingent factors thesis}

This thesis consists of explaining the performances of the U.S. economy by one or several contingent, i.e., accidental factors. We have already given an illustration of this by mentioning one of R. Gordon's articles. As a matter of fact, amongst these contingent factors, we should distinguish between those that revolve around political decisions, and those that have features that are exogenous, and even external, to the U.S. economy.

We can identify three types of contingent factors that could explain the U.S. economy's good performances (each factor explaining one aspect):

- the existence of temporary or contingent factors which play a crucial role in reducing inflation: (i) lower health-care costs translating into lower employer expenditures on health insurance in 1995, 1996 and 1997, (ii) the strong dollar, (iii) trends in raw material prices (63), (iv) the 1998 financial crisis in the emerging countries, which caused a drop in the global demand for certain products, starting with raw materials (64), etc.

- a lack of pressure on wages as a result of changes in the behaviour of employees who have become more "docile", and whose wage-related demands have become less militant. This phenomenon is supposedly explained by the fears or uncertainties that are caused by a market which has become very flexible, in an economy where restructuring operations and cost cutting programmes (and thus firings) have become very frequent. This was Alan Greenspan's explanation in 1997. Even in a full employment environment, agents are (according to Greenspan) "nervous" and insecure about the longevity of their jobs. In addition, there are a great number of "short term" contracts. If we use as an indicator the number of workers who voluntarily leave their job, it is clear that the rate is very low, and therefore that a feeling of insecurity does exist. This would mean that in an environment where institutional (the nature and length of employment contracts) and economic (firings, restructuring operations) factors are unfavourable to workers, the very mechanisms of a market economy could be one of the main explanatory factors for the lesser pressure on wages - and thus for the quasi-absence of inflation. Note that instead of formulating wage demands, workers prefer to improve their revenues by undertaking more overtime work, or by holding more than one job. In 1996, certain employees in the automobile industry worked 84 hours per week, and 7.9 million Americans held more than one job. Note in addition that given the exceptionally high level of profits, an increase in the cost of labour would be a greater threat to corporate earnings than to prices....

- the role of Alan Greenspan's conduct of monetary policy. A recent book by A. Brender and F. Pisani deals specifically with this question, and the reader should consult it for a detailed and convincing demonstration of how current economic growth can be satisfactorily explained without resorting to new explanatory mechanisms or factors (65). For these authors, the continuous expansion of activity since the early 1990s is in part due to the "way in which the Central bank has been conducting its monetary policy.... following the rule of being as pragmatic as possible." As for inflation, "careful analysis leads us to believe that this can be explained by a mechanism that is entirely reversible and hardly new, what with the drop in import prices from the mid-1980s onwards... Despite the steady drop in the unemployment rate, it has been possible to contain wage acceleration." 


\section{Is it even possible to analyse or prove the thesis that a New Economy does in fact exist?}

If we are being circumspect about the U.S. economy's current situation, this is due to two factors or elements for which we lack sufficient perspective.

The first is productivity. Productivity is a strategic factor in the New Economy in that it: (i) explains the absence of inflationary pressures on wages, (ii) determines potential growth, (iii) is an indicator reflecting the ways in which technical progress, or other phenomena, can improve the productive combination.

Given the current levels of knowledge, it is no surprise to find a certain degree of indecisiveness as to the real meaning of the trends which we observe. A significant increase in productivity, if indeed it were to be confirmed (that is, if we can disprove the idea that some statistical artefact has been used), is feasible for reasons that can be concretised over the medium term. As long as we are not assured of the structural nature of these productivity gains, we cannot exclude an explanation that focuses on factors related to cyclical adaptation.

Yet we know that, at least in principle, the cyclical adjustment of productivity is primarily manifested at the beginning of a cycle, during the recovery phase. Once a certain time has elapsed, hiring and capital accumulation can start to build up. Yet the second factor of uncertainty resides in the cycle itself. When, and in which circumstances, will the cycle be completed? The most exceptional aspect of the current cycle is undoubtedly its duration. In fact, given the brevity of the previous recession, the U.S. economy has experienced almost uninterrupted growth since 1980. However, this cycle is also unusual for another reason: it was relatively slow at the start, and really began to accelerate at a time when most people expected it to slow down.

Is it therefore clear that the American economic situation presents certain characteristics which justify a certain amount of indecisiveness, or that warrant prudence.

Another trait that calls for a modicum of indecisiveness is the length of the current expansion phase. This may be what has caused the current climate of euphoria, i.e. it could be a source of optimistic expectations. In certain respects, the U.S. economy is living (or has lived?) in the shadow of relatively widespread optimistic expectations. Admittedly, this may have lead to a certain self-fulfilling prophecy or "collective binge" in an economy that has been stringing together a series of good performances and overcoming a number of major hurdles.

This interpretation means that we can readily conceive of the existence of a speculative bubble. This hypothesis constitutes another alternative to the scenario that has developed by the New Economy's radical proponents, with their belief in the existence of a quantum leap caused by the revolution in ICT. Nevertheless, the notion does cause a few problems, insofar as we are not able to test the two explanations that are being proposed and settle the issue once and for all. As the American economist L.E. Browne wrote in a recent article comparing the situation in the United States during the 1990s with Japan's during the 1980s, "It will only be possible to distinguish between a bubble and a new era once a certain amount of time has gone by." (66) Note that this exemplifies the difficult of carrying out a technical debate on the New Economy, wherein certain theses and arguments are not even able to be tested (and are therefore non-scientific, in K Popper's utilisation of this term). 
When we find ourselves in an uncertain environment, it is tempting to turn towards comparable historical circumstances and experiences to examine the conditions in which processes akin to the current trends have unfolded in the past.

\section{The introduction of a historical and/or Schumpeterian point of view}

As we have seen, the New Economy debate appears primarily as a debate between statisticians and econometrics experts. The neo-classical theory of growth constitutes one of its main sources of methodological inspiration. Hence the interest of a major research effort in order to evaluate both the factors underlying this growth and the contributions to increases in our two forms of productivity (labour-related and factor-related). In this context, technological progress is represented by the residual value $\boldsymbol{\rho}$, which is exogenous in origin, and which can be defined as the multifactor productivity. The problem is obviously that the theory leads us to observe and measure $\rho$ 's contribution, and to record its changes (that is, any acceleration in productivity gains), without providing us with any explanation as for the reasons why the value of $\boldsymbol{\rho}$ can change. Nevertheless, this particular direction for research has shown itself to be quite fertile, given that, as we have seen, it allows us to better localise and specify the role of the computer materials producing sector.

Endogenous growth theories suggest an endogenous mode for determining $\boldsymbol{\rho}$, but these theories do not explicit the origins of these new sets of knowledge or "ideas" (to use P. Romer's expression). It is not at all clear that we will be able to advance much further in this distraction, that is, derive some advantage from an economically quantified representation of phenomena that, at least in terms of their substance, do not necessarily entertain any direct relationship with the economic aggregates that are in effect.

Ultimately, the theoretical foundations of the New Economy debate may themselves be insufficient, both at an explanatory and at a causal level.

The New Economists' theses also draw on another area of economic theory - the technological quantum leaps and long-term dynamics that are associated with capitalism. When seeking tools and analytical principles for evaluating the New Economy, it is therefore just as important to look to growth theories as to rely on history and on the Schumpeterian school of thought. Without wanting to revive old polemics, we should simply remember that Schumpeter had associated with innovation the idea of quantum leaps and radical changes in the production function. He rejected the idea of a transformation in the production function. This type of theory did not help us to predict that which should have been foreseeable, i.e., the genesis of new ideas (at least, in terms of their constituents). However, it is the source of several hypotheses concerning the dynamics of the processes at work, and on a certain number of the economic variables that they imply. Schumpeter does not provide us with any information, except expostfacto, on the nature of technological changes - but he does teach us about their rhythm, about certain factors involved in their size, and about their diffusion...

The evolutionary approach, which is one of the modern manifestations of the neo-Schumpeterian school of thought, has been illustrated by several attempts at endogenising technological progress. The models that have been developed by R. Nelson and S. Winter have contributed to a better understanding of the joint evolution of competition and technical change. (67) However, at least in terms of its constituents, technical progress remains an exotic and stochastic phenomenon. If we want to be more explicit in our dealings with its attributes, we have to resort to trajectory and paradigm concepts. By so doing, we displace the problem to another sphere, without resolving it. 
Another source of inspiration can found in analyses that cover a broader scope, that is, which deal with the conditions determining how a society assimilates an important new technology, and how it can be transformed by it. One inspiration for this perspective is the scenario developed by C. Freeman and C. Perez. Theirs is an analysis that is turns on the concept of a techno-economic paradigm, and they have used the technological revolution in computers to exemplify their proposition (68). "A vital characteristic of this... type of technical change is that it has pervasive effects throughout the economy. It not only leads to the emergence of a new range of products, services, systems and industries in its own right; but also affects directly or indirectly almost every other branch of the economy, i.e. it is a 'metaparadigm' ". This type of analysis should be seen as an extension of the Kondratiev waves theses that it attempts to bring up-to-date. In both cases, we run up against the notion of a major technological change that is being diffused throughout an entire system. In addition, this scheme integrates the delays that exist in the diffusion of the new technology, and explains how it is that such transition periods are necessary if the technology is to reach maximum efficiency. This type of analysis would seem to be entirely relevant to the constitution of a model that can be used as a benchmark for studying the U.S. New Economy. Many of the aforementioned themes can be found in it.

We can also draw lessons from a historical analysis. A few examples can demonstrate this orientation's potential contributions to the New Economy debate. What can we learn from history regarding major technological change? The literature in this area is immense, but if we restrict ourselves to the debate over the New Economy, there are least three historical reflections to which we can refer.

The first was carried out by P. David, who analysed one aspect of the electricity revolution to show that a long delay separated the invention of one of the main innovations, the dynamo, from the moment when it became a basic equipment for the entire economic system. (69) What is interesting is that we can compare this delay with that which we had observed when studying, for example, how the saturation of the stock of household appliances was affected by innovations such as the refrigerator or the electric shaver (logistic curves). With respect to the dynamo, the delay can be explained by the fact that it was necessary to invent the associated new technologies that its utilisation would require. David writes, "an extended phase of transition may be required to fully accommodate and hence elaborate the technological and organisational regime that eventually would emerge around the digital computer." In other words, the dynamo played a generic technology role, and its efficiency could not be manifested until such a time as the technologies that were required for its utilisation or to support its usage had been designed and installed.

The problem with David's analysis is that although it suggests a hypothesis in which computer technology's economic manifestations could ultimately appear (after a long delay), there is nothing in the case we are studying that says that these effects must indeed take place, and that they will be significant. The example of the dynamo illuminates one aspect of the problem, without providing any fundamental element for its corroboration: "comparaison n'estpas raison" [comparing something in not the same as justifying it].

Gordon's approach, which is also historically based, consists of comparing the impact of the computer revolution with the Second Industrial Revolution, between 1860-1900. (70) The author believes that, "it was that Second Industrial Revolution, and not the First, that created the golden age of productivity growth". This period is characterised by the "five clusters or groups that can be compared with clusters of inventions in computer hardware, software and telecommunications equipment now commonly called 'the New Economy". These are electricity; the internal combustion engine; the discovery of new 
molecules; an entire cluster of innovations related to leisure time, information and communications (telephone, telegraph, consumer photography, radio, cinema etc.); and innovations relating to people's daily lives and levels of comfort (running water, urban sanitation infrastructure).

This type of approach has contributed to the relativisation of the computer revolution. However, inasmuch as it relies on a direct empirical comparison of technological phenomena, no interconnection exists with the issue of the significance of the economic effects that we are studying, or its localisation. In addition, this comparison would appear to be disproportionate: Gordon compares a "macro invention" (computers) to a block of five "macro inventions"....

An entirely different sort of work has been undertaken by W. Nordhaus. The issue here simple, even elementary (and one that, as we have already seen, is at the heart of any statistical analysis of U.S. growth): have statisticians been sufficiently precise in their evaluations of prices? The example Nordhaus uses is the history of light since the neolithic era. Light is a specific good in the sense that, throughout history, it has provided a service that has had qualitatively invariant effects. Nordhaus observes that in nominal terms, 1000 lumens per hour cost 40 cents in 1800 - yet classical statistical methods would have evaluated this at 0.04 cents. This is a ratio of 1 to 1000 . An argument of this sort does not add anything to the debate over the New Economy, but it generates a certain amount of scepticism concerning the data that economists use to study long-term trends, and thus concerning the significance of their findings. This question over the data being used is not a new one (Crafts [71]). It indicates the direction in which a substantial part of research efforts should be aimed.

These historical approaches provide interesting arguments, but their value is purely suggestive, and partial at best. We must therefore turn to historical economists, and to the analyses that they offer us of the technological revolutions that have taken place. We can use this as an illustration of the lessons that we can learn from such an approach, and thereby infer where we should direct research on topics that the New Economy debate has hitherto left untouched.

- Technology is not an input like the others. Its advance depends on previous knowledge and on combinations that are sometimes mysterious (J. Mokyr [72], M.Weitzmann...). Knowledge accumulation systems are not conservative in the physical sense of the term.

- This evolution also depends on institutions, economic policy and on history: path dependency phenomena play a role. An orientation of this sort approximates the national innovation system approaches that Lundvall, in particular, has been promoting. Applied research on this topic can be very instructive (B. Amable, R. Barré, R. Boyer [73]).

- Innovations can require a long time before reaching economic maturity (P. David, plus Crafts' cotton textiles example).

- Macro-inventions play a major role (J. Mokyr).

- Human capital plays a significant role in growth processes (Crafts).

The question we should be asking before concluding this review is of a theoretical, methodological and historical sort: what kinds of relationship should we be expecting between technological change and macroeconomic performances; and more specifically, between technological change and apparent activity. If we are trying to ascertain whether ICT plays a crucial role or not, it is less important to use a 
statistical approach than to find out whether the statistical data that is available will necessarily translate the importance of ICT. In other words, is the data, interpreted in the proper manner (as discussed above) a sufficient test of the hypothesis that a technological regime has truly changed? In one example, using multifactor productivity as a criterion, Crafts has demonstrated that during the $19^{\text {th }}$ century, and more specifically at the time of the Industrial Revolution, Great Britain featured a value that would have only ranged between 0.4 and $0.8 \%$. This tends to suggest that technological revolutions can take place without their showing up in high multifactor productivity values.

One reason to reply in the negative, or at least to be cautious, is that the conditions for an aggregation of productivity gains are far from having been elucidated. There is the possibility that productivity gains are "dissimulated", or captured "locally", whenever the productive system, taken as a whole, has not achieved a more or less stable industrial organisation. We can strengthen this argument by observing that a technological revolution translates into the implementation of a new productive system, but that this latter does not stabilise immediately if it is a new technological paradigm that is emerging. However, in case the paradigm is changing, threshold effects and complementarities come into the equation, and productivity gains will only appear once a certain infrastructure or global architecture has been set up: a material infrastructure (i.e., cable links), an infrastructure of norms, property rights... Moreover, this structure should not be seen as something that has been prefabricated, that is, which is pre-existing and waiting to be "discovered". It must be built collectively, resulting from "research" efforts and from collective learning. This means that, in these sorts of situations, we should be focusing on a historical type of research rather than on statistical analyses that see no difference between configurations whose dynamics may very possibly signify things that are quite different. The path dependency of an innovation, with respect to its constituents, does not necessarily make a good couple with a solely quantitative approach.

On this score, we note that any interpretation which relies on long-term dynamics implies the existence of a certain number of disequilibria that the dynamic itself will need to resolve.

\section{Conclusion}

The New Economy concept first arose in the mid-1990s, that is, at a watershed period. It is noteworthy that in certain respects, the New Economy school of thought, in the light of the situation in 1994-1997, has not been entirely contradicted by that which subsequently occurred, during the latter half of the 1990s. U.S. growth continued to be strong and non-inflationary, with an unemployment rate that was exceptionally low. Productivity gains were high; a large number of statistical revisions took place (but did not always modify these gains as anticipated or even desired). The stock market continued to hit record highs despite sporadic market corrections; no real Crash took place; and the economy overcame several crises without any real interruption in economic growth.

However, these events are not enough to validate a stance whose form and style clearly involve, at least with certain authors, out and out utopianism. After all, it is always possible to be right sometimes, even when using the wrong arguments (or no arguments at all).

It is not all certain that we dispose of a sufficient number of points of reference to develop a set position on whether or not these changes in productivity rates have involved something that is structural in nature. First of all, the most recent official data available on multifactor productivity dates from $1997^{2}$.

\footnotetext{
${ }^{2}$ From 1998 since september 20.
} 
Secondly, certain problems of a statistical kind do exist. Furthermore, the current cycle is so atypical in its development that we cannot exclude a cyclical explanation for the gains in average aggregate productivity, albeit over a seemingly long period of time. The U.S. economy's growth rate did leap forward in 1995-96, and has remained at a high level ever since. The annual rate has never been lower than $2.4 \%$, and the average real GDP growth rate over the 1991-1999 period was $3.6 \%$

The concept of a New Economy is a source of confusion. One reason is that the definitions associated with it are diverse, sometimes significantly different from one another, and as a result, the concept is a source of semantic confusion. Another source of puzzlement stems directly from what we have learned from some recent statistical research into this changing productivity, and the way in which it rebounded during the latter half of the 1990s.

In its radical and original meaning, the New Economy concept actually focuses on the notion of ICT diffusion, and on the generalisation of productivity gains. The idea is that these phenomena are due to technological externalities (74), and to a knock-on effect such as the one suggested in the endogenous growth theory and in the evolutionary approach to innovation. Some feel that the real catalyst underlying these trends has been the technological improvement that has been induced by ICT, which can be considered as a generic technology. In reality, it is the opposite that we have witnessed. Technical progress has only been economically manifest in those sectors that produce new ICT-related equipment; and user sectors are at best only affected through their accumulation of such equipment investments that have been facilitated by reductions in the equipment's price (and accentuated by its obsolescence rates). We thus arrive at a vision of ICT-related productivity gains that is totally different from the one offered by the New Economy concept.

On this note, the Solow Paradox has neither been entirely resolved nor superseded. It is true that, at an aggregate level at least, the productivity slowdown appears to have more or less gone away; and that we have indeed seen manifestations of computer-engendered productivity gains. Nevertheless, sectorial analysis has demonstrated that a few sectors remain where we still "see computers everywhere - [just not always] in the statistics."

\section{FOOTNOTES}

1. In "We'd better watch out”, New York Times Book Review, 12 July 1987.

2. On this point, read A. Englander and A. Mittelstädt, "La productivité totale des facteurs : aspects macro-économiques et structurels de son ralentissement", Revue économique de l'OCDE, n¹0, spring 1988, and S. Englander et A. Gurney, "Croissance de la productivité dans la zone de l'OCDE : tendances à moyen terme ", Revue économique de l'OCDE, n²2, spring 1994.

3. Here we draw our inspiration from the title of L. Sfez's book, La santéparfaite. We will be returning later to this perfection theme.

4. The indicator we use here is non farm business productivity, as measured until early 1996.

5. The present text is in part inspired from its author's other works: L'utopie néo-libérale de la New Economy, a working document, Université Paris 1, laboratoire I.SY.S.-MATISSE, July 1999 ; La "New economy" : 
enjeux et limites, Quadern, winter 1999 ; L'utopie libérale de la "New economy", Quaderni, autumn 2000 ; De la New Economy au capitalisme cognitif, Multitudes, n², 2000.

6. A technology is generic if it can be combined or interlinked with existing or other technologies to give birth to new methods for designing products, to new manufacturing techniques, and to new forms of organisation. Such a technology is diffusable if it is the only source of the new technical processes and intermediary goods that are being diffused throughout the entire economy. The concept of a General Purpose Technology (G.P.T.) encompasses these two aspects : A G.P.T. "transforms an economy by finding many new lines of application, and fusing with existing technologies to rejuvenate other, pre-existing sectors of the economy" (P. David, 1999, p. 18)

7. Don Tapscott, Digital Economy, McGraw-Hill, 1996.

8. M. Fraumeni, M. E. Manseret T. L. Mesebourg, Government Statistics: e-commerce and the electronic economy, paper prepared for the Federal Economic Statistics Advisory Committee, 15 June 2000.

9. U.S. Department of Commerce, Economics and Statistics Administration, Digital Economy 2000, June 2000.

10. “Distances are reduced in a Weightless Economy ”, Wall Street Journal, 25 January 1999

11. Cf. inter alia : R. Khaber, C. Parisot et J.-L. Mourier, La France à l'heure des technologies de l'informtion, Le point Mensuel, May 1999, Aurel-Leven.

12. Alan Greenspan's positions seem to have evolved recently, and he has moved closer to this third defintion of the New Economy, without having entirely adhered to it.

13. S. Shepard, “The New Economy: What it Really Means ”, Business Week, 17 November 1997, pp. 48-50.

14. P. Schwartz et P. Leyden, “The Long Boom”, Wired, n 5.07, July 1997.

15. The other technological waves are comprised of biotechnology, nanotechnology and alternative energies.

16. E. Yardeni, Weekly Economic Analysis, Deutsche Morgan Grenfell, 3 February 1997.

17. In traditional neo-classical economics, externalities, collective goods, and indivisible factors are considered as exceptions or "failures" of the market (using M. Bator's expression). Nowadays, the problem is that these exceptions lie at the heart of the core constituent of modern economics - information. Hence certain economists' need to undertake a wholesale revision of economic laws

18. Cf. the seminal article by K. Arrow, "Economic Welfare and the Allocation of Resources for Invention ", in The Rate and Direction of Inventive Activity, NBER, Princeton University Press, 1962. It is also worth consulting P. Petit ed., L'économie de l'information, La Découverte, 1998.

19. C. Shapiro et H. R. Varian, Information Rules, Harvard Business School Press, 1999.

20. This takes nothing away from the relevance of statistical studies that purport to measure the constituents and possible impact of the digital economy, nor from the relevance of the studies that have been devised by the B.E.A. (Burean of Economic Analysis) or by the E.S.A., both of which are departments of the U.S. Department of Commerce. This study presents the clear advantage of laying out and expliciting all of the issues that are involved in any attempt to evaluate and measure these phenomena. As such, it is radically different from the very personalised and implied usage that a certain section of the media (particularly the financial or stock market media) has been making of these studies.

21. The various forms of the new/New Economy have been outlined in L'utopie néo-libérale de la New Economy, op. cit., which can be obtained from the present study's author (Maison des Sciences Economiques, 106, Bd de l'Hôpital, Paris, 75013).

22. The previously announced figure of $5.5 \%$ has been revised downwards.

23. There has of course been a historical trend in way in which this rate has changed.

24. Calculations made using the series GDP in chained dollars (1996) published by the Bureau of Economic Analysis.

25. This involves " real" (corrected for inflation) income, after taxes.

26. Information drawn from " Desperately seeking a perfect model ", The Economist, 16 May 1999.

27. Anne-Cécile Robert, “Faux emplois et vrais chômages ”, Le Monde Diplomatique, April 1998.

28. According to a comparative international study carried out by the ILO. For the same year, the annual average of hours worked was 1656 in France, and 1399 in Norway. 
29. P. Blanqué, US Credit Bubble. Com, in Bulletin de Conjoncture de Paribas, April 1999.

30. By"cumulative", we mean by combining the two types of revision.

31. Monthly Labor Review, October 1995. Tableau de la page 31.

32. Cf. Englander's studies published in the OECD's Economic Review, as cited.

33. Z. Griliches, "Productivity, R\&D and the Data Constraint", American Economic Review, March 1994, vol. 84.

34. In the mid-1990s, non-farm business products accounted for about $75 \%$ of GDP.

35. Note that in autumn 1995, the Bureau of Economic Analysis moved from a fixed-weighted measurement of production, expressed in volumes, to a chain-weighted measurement. The figures that we have reproduced here, in this paragraph, result from the fixed-weighted measurements.

36. A. J. Filardo, "Has The Productivity Trend Steepened in the 1990s ?", Economie Review, 4Q 1995, Federal Reserve Bank of Kansas City. The finding that we have cited relates to the chain-weighted series measurements that do not take any cyclicality into account (and more specifically, to the 1990-91 recession.)

37. We should stress that overall non farm business productivity dropped by almost 4\% between 1Q 1990 and 1Q 1992.

38. These are chain-weighted measurements that have been adjusted to account for cyclical factors.

39. Cf. C. A. Garner, An Inflation Report for 1999, Economic Review, Federal Reserve Bank of Kansas City, 1Q 2000.

40. We are using the latest figures published by the Burean of Labor Statistics.

41. Numbers taken from P. W. Bauer, Are We in a Productivity Boom? Evidence from Multifactor Productivity Growth, Federal Reserve Bank of Cleveland, 15 October 1999.

42. J. Bradford De Long, Introduction to the Symposium on Business Cycles, Journal of Economic Perspectives, vol. 13, n², Spring 1999

43. This is a mere coincidence, but Gordon's article actually starts out by invoking "The miracle of U.S. economic performance in the late 1990".

44. I.N.S.E.E., Note de Conjoncture Internationale, June 1999, pp. 31-32.

45. R. Gordon, op. cit., p. 7.

46. R. Gordon, $W$ as the Economy of the 1990s a New One?, CBO New Economy Briefing dated 6 June 2000.

47. A generic technology is one that can be widely diffused throughout an economy, and which, when combined with certain specific technologies, will give birth to new technologies, and to new processes. An example of this is the interaction between mechanics and electronics, which gave birth to the field of mechatronics. (cf. n. 6 supra)

48. Digital Economy 2000, U.S. Department of Commerce, June 2000, p.1.

49. "Y-a-t-il eu accélération du progrès technique aux Etats Unis ? " Note de conjoncture internationale de l'I.N.S.E.E., December 1999, p. 25.

50. On this point, cf. E. Lefeuvre et P. Sicsic, “Nouvelle technologie et productivité aux Etats Unis ”, Flash du service de la recherche de CDC Marchés, n²000-137, 18 July 2000.

51. S. O. Oliner et D. E. Sichel, The Resurgence of Growth in the Late 1990s: Is Information Technology the Story?,, working paper, February 2000.

52. Cf. above all D. Jorgenson et K. Stiroh, Information Technology and Growth, American Economic Review, vol. 89, n², May 1999 ; D. Jorgenson et K. Stiroh, U.S. Economic Growth at the Industry Level, working paper, December 1999 ; D. Jorgenson et K. Stiroh, Raising the Speed Limit: U.S. Economic Growth in the Information Age, working paper, May 2000.

53. R. Gordon, Has the New Economy Rendered the Productivity Slowdown Obsolete ?, working paper, Northwestern University, June 1999.

54. This point is developed in B. Paulré, L'utopie néo-libérale de la New Economy, op. cit.

55. D. Jorgenson and K. Stiroh, U.S. Economic Growth at the Industry Level, op. cit.

56. R. Ruyer, L'utopie et les utopies, P.U.F., 1950.

57. M. Le Roy, Logique de l'invention, quoted by R. Ruyer, op. cit., p. 12.

58. N.A.I.R.U. : Non-Accelerating Inflation Rate of Unemployment.

59. The U.S. unemployment rate dropped below 5.5\% in 1995-1996 
60. Cf. for example an exposé by B. Bluestone and B. Harrison, "Why We Can Grow Faster", The American Prospect, September 1997, $\mathrm{n}^{\circ} 34$. They estimate at 0.3 to $0.4 \%$ the margin of error for each of these two growth rates, justifying a potential growth rate for the United States of around 3\% (i.e., 2,4 \% + 2*0,3\%).

61. P. Krugman, “How Fast Can the U.S. Economy Grow ?”, Harvard Busines Review, July 1997.

62. A reinterpretation that initially stays in touch with the "real world" and does not make any radical departure from this.

63. As pertains to the price of oil at least, we see that low prices are temporary - after all, starting in 1999, the price trend is much higher. There has already been a large increase over the past twelve months.

64. In 1998, world production rose by 2\%, whereas it had risen by 4\% in 1997 .

65. A. Brender et F. Pisani, Le nouvel âge de l'économie américaine, Economica, 1999.

66. L. E. Brownie, “U.S. Economic Performance : Good Fortune, Bubble or New Era? ”, New England Economic Review, May 1999.

67. R. Neslon et S. Winter, An evolutionary theory of economic change, Cambridge, Belknap, 1982.

68. C. Freeman et C. Perez, "Structural crisis of adjustment: business cycles and investment behavior", in G. Dosi et alii (eds), Technical change and Economic Theory, Pinter Publ., 1988.

69. P. David, "The Dynamo and the Computer: An historical Perspective on the Productivity Paradox", Amercan Economic Review, vol. 80, n², May 1990 and Understanding Digital Technology's Evolution and the Path of Measured Productivity Growth, SIEPR Discussion paper n 99-11, Standford, January 2000.

70. R. Gordon, Does the "New Economy" Measure up to the Great Inventions of the Past?, to appear in the Journal of Economic Perspectives, April 2000.

71. N. F. R. Crafts, "The First Industrial Revolution: A Guided Tour for Growth Economists", American Economic Review, vol. 86, n², May 1996.

72. J. Mokyr, The lever of riches, Oxford University Press, 1990.

73. B. Amable, R. Barré et R. Boyer, Les systèmes d'innovation à l'ère de la globalisation, Economica, 1998.

74. We should stress that these are technological rather than monetary (pecuniary) externalities. 